\title{
When starting with the most expensive option makes sense: Optimal timing, cost and sectoral allocation of abatement investment
}

\author{
Adrien Vogt-Schilb ${ }^{\mathrm{a}, *}$, Guy Meunier ${ }^{\mathrm{b}}$, Stéphane Hallegatte ${ }^{\mathrm{c}}$ \\ a Inter-American Development Bank, Climate Change Division, Washington, DC, USA \\ ${ }^{\mathrm{b}}$ INRA-UR1303 ALISS, Ivry-Sur-Seine, France \\ ' The World Bank, Climate Change Group, Washington, DC, USA
}

\section{A R T I C L E I N F O}

\section{Article history:}

Received 29 July 2015

Available online 12 December 2017

\section{JEL classification:}

Q54

Q52

Q58

\section{Keywords:}

Climate change mitigation

Transition to clean capital

Path dependence

Social cost of carbon

Marginal abatement cost

Timing

\begin{abstract}
A B S T R A C T
This paper finds that it is optimal to start a long-term emission-reduction strategy with significant short-term abatement investment, even if the optimal carbon price starts low and grows progressively over time. Moreover, optimal marginal abatement investment costs differ across sectors of the economy. It may be preferable to spend $\$ 25$ to avoid the marginal ton of carbon in a sector where abatement capital is expensive, such as public transportation, or in a sector with large abatement potential, such as the power sector, than $\$ 15$ for the marginal ton in a sector with lower cost or lower abatement potential. The reason, distinct from learning spillovers, is that reducing greenhouse gas emissions requires investment in long-lived abatement capital such as clean power plants or public transport infrastructure. The value of abatement investment comes from avoided emissions, but also from the value of abatement capital in the future. The optimal levelized cost of conserved carbon can thus be higher than the optimal carbon price. It is higher in sectors with higher investment needs: those where abatement capital is more expensive or sectors with larger abatement potential. We compare our approach to the traditional abatement-cost-curve model and discuss implications for policy design.
\end{abstract}

(c) 2017 Published by Elsevier Inc

\section{Introduction}

Governments around the world have committed to stabilize climate change to mitigate subsequent damages (G7, 2015; UNFCCC, 2016). Stabilizing the climate will require transitioning from an economy based on polluting capital, such as inefficient buildings and polluting cars, to an economy based on clean capital, such as retrofitted buildings or electric vehicles. A critical question for public policy is to determine the optimal cost and timing of such abatement investment. Is action as urgent as frequently advocated? A second important issue is the optimal allocation of abatement. There are many options to reduce greenhouse gas (GHG) emissions, from renewable power plants to improved building insulation and more efficient cars. Each of these options has a cost, and would reduce emissions by a certain amount. Should emission-reduction investments start with the least expensive options and progressively clean the economy by ascending cost order?

To shed light on these questions, we study the optimal timing, cost, and sectoral allocation of abatement investment. We

\footnotetext{
* Corresponding author.

E-mail addresses: avogtschilb@iadb.org (A. Vogt-Schilb), guy.meunier@ivry.inra.fr (G. Meunier), shallegatte@worldbank.org (S. Hallegatte).
} 
capture the transition to clean capital using a parsimonious abatement investment model with three basic features. First, emission reductions require investment that has long-lasting effects on emissions. For instance, once a building is retrofitted with better insulation, emissions from that building are lowered for decades.

Second, we take into account the limited ability of an economy to switch from carbon-intensive to low-carbon capital overnight. We model this with convex investment costs, sometimes called adjustment costs in the theory of investment (Lucas, 1967; Gould, 1968). They capture increasing opportunity costs to use scarce resources, such as skilled workers and appropriate capital, to perform abatement investment. For instance, retrofitting all buildings in a country in three months would be much more expensive than doing it over three decades.

Third, we take into account that different GHG emissions in each sector mean different abatement potentials in each sector. Once all the buildings are energy neutral, no more GHG can be saved in the building sector; and if every coal power plant is replaced with renewable power, the abatement potential of the power sector is depleted.

This paper is the first to disentangle the optimal carbon price, the optimal timing of emission reduction, and the optimal abatement investment pathways in a multi-sector analytical model. Our analysis brings three main findings.

First, while the optimal carbon price increases over time (a familiar result), the optimal abatement investment profile is bell-shaped (increasing, then decreasing over time) or even strictly decreasing. In particular, a growing carbon price is compatible with significant short-term investment.

Second, optimal marginal abatement investment costs, expressed in dollars invested per discounted abated ton of carbon (a metric called the levelized cost of conserved carbon, or sometimes simply the marginal abatement cost), can be higher than the carbon price.

Third, the levelized cost of conserved carbon should be higher in sectors where abatement capital is more expensive and sectors with higher abatement potential.

These results provide counter-intuitive policy guidance, as they suggest that more investments should be done in the sectors with higher costs, and that optimal investment may start higher than what the social cost of carbon would suggest. For instance, when abatement options are presented in a marginal abatement cost curve à la McKinsey (2009), it may be desirable to implement some of the "expensive" measures on the right-hand side of the curve, even if their cost appears higher than the carbon price, or higher than the cost of alternative abatement options in the curve (see also Vogt-Schilb et al., 2015). In a numerical simulation, we find that an abatement option at $25 \$ / \mathrm{tCO}_{2}$ in the industrial sector may be preferable to a $15 \$ / \mathrm{tCO}_{2}$ option in the building sector, because the industrial sector is both more expensive to decarbonize and has a greater abatement potential than the building sector.

The reason is that to cope with the increasing carbon price, all sectors should eventually be decarbonized. In each sector, two factors drive the optimal speed at which to deploy abatement capital to reach this goal: the magnitude of the transition to zero carbon, captured by the abatement potential; and the availability of appropriate resources (such as skilled workers and production lines), captured by adjustment costs. At any point in time, sectors where unabated emissions are higher and sectors where abatement capital is more expensive should receive more abatement investment, to smooth their transition and reduce adjustment costs.

The intuition behind this result is as follows. Abatement investment reduces emissions and transmits abatement capital to the future. Therefore, the current value of abatement investment (and the levelized cost of conserved carbon) depends on two factors: the carbon price, which is the same in all sectors, and the value of abatement capital in the future, which is greater in sectors with higher investment needs, that is those facing higher emissions or higher adjustment costs.

Our findings contrast with those from the literature on the optimal timing of GHG emission reductions. Since the seminal contributions by Nordhaus (1991, 1992), which have established the DICE model as a reference framework for analysing this question (Dietz and Stern, 2014), studies have found that abatement effort should start low and grow over time. We show that this result comes from the fact that in DICE, abatement can be chosen at each point in time on an abatement cost curve, independently of previous abatement (see Nordhaus and Sztorc, 2013 and Appendix G).

In a model based on abatement cost curves, the optimal carbon price, the quantity of abatement and the abatement cost increase together over time. In particular, contemporaneous mitigation action, relevant for today's decision makers, is desirable only if today's carbon price is high enough. Advocates of early voluntarism in climate mitigation, such as Stern (2006), have proposed modifications in DICE that would result in higher short-term carbon prices, hence higher abatement in the short term (Dietz and Stern, 2014; Espagne et al., 2012). Here, we show that modelling long-lived abatement investment allows disentangling the optimal carbon price, the optimal cost of emission reductions, and the optimal timing of emission reductions. In particular, ambitious investment today makes sense even if the carbon price today is low.

We illustrate this difference with a numerical comparison of an abatement-cost-curve model and an abatement-investment model, calibrated with the same sectoral costs and potentials from IPCC data, and with the same economy-wide carbon budget. While the two models essentially agree on the optimal carbon price, they lead to radically different emission reductions and abatement effort in the short term. The abatement-cost-curve model recommends spending 100 billion dollars on mitigation the first year and, perhaps unrealistically, to reduce as much as $12 \mathrm{GtCO}_{2}$ that same year (about forty percent of global emissions). In contrast, the abatement-investment model recommends spending 300 billion dollars the first year, while reducing less than $1 \mathrm{GtCO}_{2}$. In contrast to the cost-curve approach, the abatement-investment framework acknowledges that substantial emission reductions cannot happen overnight, but still require substantial short-term investment. Abatement investment reconciles the familiar finding that climate objectives impose a shadow price of carbon that increases over time with the need for immediate and significant abatement investment stressed by the international 
community (e.g., NCE, 1977; IPCC, 2014b; World Bank, 2015).

Other analytical papers have also concluded that it can make sense to invest early in the transition to a zero-carbon economy, but the literature has tended to focus on the role of knowledge accumulation. If abatement brings a second benefit in the form of knowledge accumulation, then abatement effort should generally be larger than what the carbon price alone would suggest (Wigley et al., 1996; Goulder and Mathai, 2000; Popp, 2004; Kverndokk and Rosendahl, 2007; Acemoglu et al., 2012). Previous research finds that when comparing two competing abatement technologies, such as solar versus wind, society should spend more in technologies more prone to learning spillovers (Rosendahl, 2004; Bramoullé and Olson, 2005; del Rio Gonzalez, 2008).

Our analysis provides a different rationale for investing early and discriminating between emission-reduction options: it shows a need for early investment in equipment that will take time to deploy (such as clean power plants or public transport infrastructure), especially in sectors with large baseline emissions or large abatement costs. The distinction is important: a given sector, such as perhaps public transportation, can be subject to negligible learning dynamics, but still require early investments for the reasons exposed in this paper. And operational consequences differ: putting researchers to work on better wind turbines and starting to deploy wind turbines are not the same things. ${ }^{1}$

Finally, our results provide theoretical insights to reinterpret previous numerical results. Several studies using complex Integrated Assessment Models (IAMs) stress the importance of aligning short-term emission reduction action with longterm emission reduction targets: given the limited ability of economies to switch overnight to low-carbon technologies, if short-term efforts are too modest, subsequent efforts will need to be much stronger (Iyer et al., 2014; Riahi et al., 2015; IPCC, 2014b). Further, several authors have shown that what matters is not only the amount of short-term effort, but also in which sectors it happens (Lecocq et al., 1998; Jaccard and Rivers, 2007; Vogt-Schilb et al., 2015). ${ }^{2}$ By using an analytically tractable model, this paper clarifies that short-term emission reduction expenses need to be higher than what the carbon price alone suggests, and should focus in the sectors that will be more difficult to decarbonize. It also clarifies that effort may mean two different things: expenses and emission reductions. We show that sectors where abatement investment is more expensive should receive more abatement expenses (in $\$ / \mathrm{tCO}_{2}$ ), without necessarily generating more emission reductions (in $\mathrm{tCO}_{2}$ ) than sectors where reductions are cheaper.

The paper proceeds as follows. Section 2 presents the abatement investment model. Section 3 derives results concerning the optimal timing of abatement investment. Section 4 examines the optimal cost of emission reductions. Section 5 investigates the optimal allocation of abatement investment across sectors. Section 6 compares abatement investment and abatement cost curves with numerical illustrations calibrated with IPCC data. Section 7 concludes on policy design.

\section{Model}

A social planner (or an equivalent well-functioning market facing the socially-optimal carbon price) needs to constrain cumulative GHG emissions below a given ceiling, or carbon budget $B$. The carbon budget $B$ can be interpreted as the allowable emissions to stabilize global warming to a given temperature target (IPCC, 2014b), or as a tipping point beyond which the environment is catastrophically damaged. This keeps the model as simple as possible, and allows us to focus on the dynamics of emission reductions costs, keeping the dynamics of climate change and climate damages out - that is abstracting from the benefits of emission reductions. ${ }^{3}$ Appendix B shows that the results exposed in this paper hold in a costbenefit analysis framework.

We denote $m_{t}$ the cumulative atmospheric emissions at date $t$. The emission dynamics and carbon budget read (dotted variables represent temporal derivatives):

$$
\begin{aligned}
& m_{0} \text { given } \\
& \dot{m}_{t}=\varepsilon_{r e f}-a_{t} \\
& m_{t} \leq B
\end{aligned}
$$

Where $\varepsilon_{\text {ref }}$ represents baseline emissions, and $a_{t}$ represents abatement at time $t$. Baseline emissions $\varepsilon_{\text {ref }}$ can also be interpreted as the maximum abatement potential, in the sense that

\footnotetext{
1 There are other differences between capital and knowledge accumulation. For instance, knowledge accumulation can continue to reduce costs once emissions are entirely abated, but it does not make sense to accumulate more abatement capital than what suffice to reduce emissions down to zero. Spillovers is a prominent feature of most knowledge accumulation related to climate mitigation, while private ownership is a feature of most power plants, vehicles and buildings, clean or dirty. In addition, a key component of capital is its turnover rate, which is not necessarily linked to the obsolescence of the knowledge used to built it (as illustrated by old bridges and buildings in use in Europe). It remains an avenue for further research to account for the two phenomena in a single model.

2 These papers use toy numerical models. We are unaware of any IAM study reaching this conclusion yet.

${ }^{3}$ In simple economic theory, the ideal approach to determine the initial price of carbon is to perform a cost-benefit analysis. Due to the various scientific uncertainties surrounding climate change and resulting damages, assessing the benefits from climate mitigation is not straightforward (Manne and Richels, 1992; Ambrosi et al., 2003; Stern, 2013; Pindyck, 2013), and it is common to use targets expressed in global warming (such as the $2{ }^{\circ} \mathrm{C}$ target from the Paris Agreement, or any other temperature target), or, similarly, cumulative emissions also known as carbon budgets (Allen et al., 2009; Matthews et al., 2009; Zickfeld et al., 2009).
} 


$$
\forall t, a_{t} \leq \varepsilon_{r e f}
$$

To reduce emissions, one must invest in abatement capital, which has a long-lived effect on emissions. Borrowing the wording by Davis and Socolow (2014), investment in electric vehicles or building retrofitting is a hard commitment to emit less GHG during the lifetime of this equipment. For simplicity, abatement capital is directly measured in terms of avoided emissions, and baseline emissions are assumed constant (this assumption is relaxed in E.2). We also assume the stock of abatement capital starts at zero (without loss of generality). None of these three simplifying assumptions are essential to derive our results, but they considerably ease exposition.

At each time step $t$, the positive amount of abatement investment $x_{t}$ adds to the abatement capital stock $a_{t}$, which otherwise depreciates at rate $\delta$ :

$$
\begin{aligned}
& a_{t_{0}}=0 \\
& \dot{a}_{t}=x_{t}-\delta a_{t}
\end{aligned}
$$

Abatement investment costs $c\left(x_{t}\right)$, where the function $c$ is positive, increasing, differentiable and strictly convex:

$$
\begin{aligned}
\forall x_{t}, & c^{\prime \prime}\left(x_{t}\right)>0 \\
& c^{\prime}\left(x_{t}\right) \geq 0 \\
& c\left(x_{t}\right) \geq 0
\end{aligned}
$$

$c^{\prime}\left(x_{t}\right)$ is referred to as the marginal abatement investment cost. The convexity of the abatement investment cost $c$, sometimes referred to as adjustment costs (Lucas, 1967; Gould, 1968; Mussa, 1977), captures increasing opportunity costs to use scarce resources (skilled workers and appropriate capital) to build and deploy abatement capital. ${ }^{4}$ The marginal investment cost $c^{\prime}$ can simply be seen as the marginal cost curve for the industry that supplies abatement investment - e.g., clean vehicle manufacturers or insulation contractors.

For instance, $x_{t}$ is the pace - measured in buildings per year - at which old buildings are being retrofitted at date $t$ (the abatement $a_{t}$ would then be proportional to the share of retrofitted buildings in the stock). Retrofitting buildings at a given pace requires to pay a given number of scarce skilled workers. If workers are hired in the merit order and paid at the marginal productivity, the marginal price of retrofitting buildings $c^{\prime}\left(x_{t}\right)$ is an increasing function of the pace $x_{t}$. The cost $c\left(x_{t}\right)$ may also be interpreted as the net present cost of building and operating low-carbon capital (e.g., an electric vehicle) instead of, or in replacement for, polluting capital.

The social planner (or equivalent decentralized procedure) chooses when to perform abatement investment in order to meet a carbon budget at the lowest inter-temporal cost, under the constraint set by the maximum abatement potential $\varepsilon_{\text {ref }}$ :

$$
\begin{array}{ll} 
& \min _{x_{t}} \int_{0}^{\infty} e^{-r t} c\left(x_{t}\right) d t \\
\text { subject to } & m_{t} \leq B \quad\left(\phi_{t}\right) \\
& \dot{m}_{t}=\varepsilon_{r e f}-a_{t} \quad\left(\mu_{t}\right) \\
& \dot{a}_{t}=x_{t}-\delta a_{t} \quad\left(\nu_{t}\right) \\
& a_{t} \leq \varepsilon_{r e f} \quad\left(\lambda_{t}\right)
\end{array}
$$

Importantly, one does not control directly abatement $a_{t}$, but abatement investment $x_{t}$, linked to the temporal derivative of $a_{t}$. For instance, one controls and pays for a number of buildings to retrofit each year, which indirectly translates to a total share of retrofitted buildings in the stock, which in turn translates to reduced GHG emissions flows.

The Greek letters in parentheses are the co-state variables and Lagrangian multipliers (chosen in current value and such that they are positive): $\nu_{t}$ is the shadow value of abatement capital, $\mu_{t}$ is the shadow price of carbon emissions, and $\lambda_{t}$ is the shadow price of the maximum abatement potential $\varepsilon_{\text {ref }}$, that quantifies the scarcity of investment opportunities. In the following, we refer to co-state variables and Lagrangian multipliers as "prices", instead of "shadow prices", for short.

\section{Optimal timing of abatement investment}

We start the resolution of problem 6 from the steady state. The cumulative emission ceiling $B$ is reached at an endogenous date $T$. After $T$, emissions net of abatement are nill, meaning that the abatement potential $\varepsilon_{\text {ref }}$ is reached, and abatement investment only compensates for depreciation (Appendix A):

\footnotetext{
${ }^{4}$ We thus assume that some factor required to build low-carbon capital is in fact scarce. During the recent economic depression, some argued that the government could perform a green stimulus by hiring idle resources (unemployed workers and under-used capacities) to build low-carbon equipment. This possibility is not covered by the model used in this paper.
} 


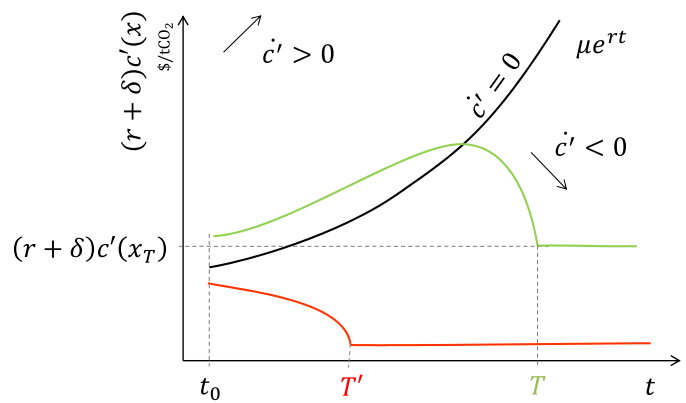

Fig. 1. The carbon price and the two possible optimal abatement investment pathways. While the carbon price grows exponentially over time, the optimal abatement investment cost $(r+\delta) c^{\prime}\left(x_{t}\right)$, and thus optimal investment $x_{t}$, may either draw a bell shape or decrease over time.

$$
\begin{aligned}
\forall t \geq T, \quad m_{t}=B \\
\Longrightarrow a_{t}=\varepsilon_{\text {ref }} \\
\Longrightarrow x_{t}=\delta \varepsilon_{\text {ref }}
\end{aligned}
$$

Before $T$, the optimal shadow price of carbon $\mu_{t}$ increases at the discount rate $r$ (Appendix A demonstrates this familiar result):

$$
\forall t<T, \quad \mu_{t}=\mu e^{r t}
$$

The initial carbon price, $\mu_{t_{0}}$, is endogenously chosen at the lowest value such that the carbon budget is met.

The exponentially-increasing carbon price is reminiscent of an Hotelling rule. It ensures that the present value of the carbon price is constant along the optimal path until full decarbonization, such that the social planner (or the market) is indifferent between one unit of abatement at any two dates. (Section 5 shows that this Hotelling rule does not translate to a straightforward Herfindhal principle: that is, abatement opportunities should not be exploited starting with those that have the lowest levelized cost of conserved carbon.).

Before $\mathrm{T}$, emissions are strictly positive, abatement capital is lower than its potential $a_{t}<\varepsilon_{\text {ref }}$, and optimal investment dynamics are described by the first order condition (Appendix A):

$$
\forall t<T, \quad(r+\delta) c^{\prime}\left(x_{t}\right)-\frac{d c^{\prime}\left(x_{t}\right)}{d t}=\mu e^{r t}
$$

We call the left hand side of (9) the marginal implicit rental cost of capital, adapting to the case of endogenous capacity prices the concept of implicit rental cost of capital first proposed by Jorgenson, 1967. It is the rental price that ensures agents would be indifferent between buying abatement capacity at $c^{\prime}\left(x_{t}\right)$ or renting it at the rental price.

The expression of the rental price translates that there is no profitable tradeoff between the two following strategies: (i) buy capital at $t$ at a cost $c_{i}^{\prime}\left(x_{i, t}\right)$, rent it out during one period $d t$ at the rental price, then sell the depreciated $(\delta)$ capacities at $t+d t$ at a price $c^{\prime}{ }_{i}\left(x_{i, t}\right)+\frac{d}{d t} c^{\prime}{ }_{i}\left(x_{i, t}\right) d t$ or (ii) simply lend money at the interest rate $r$ (Jorgenson, 1967). Appendix D proposes an alternative explanation of the marginal implicit rental cost of abatement capital.

Eq. (9) thus simply means that if there was a well-functioning market for abatement capital, the rental cost of abatement capital would be equal to the carbon price. For instance, consider a taxi company that meets a fixed demand for travel, rents the vehicles it uses, and pays a carbon tax on the carbon it emits. Consider the taxi company faces two similar vehicles available for rent, differing only in their carbon emissions and rental price. Eq. (9) suggests the company will chose the cleaner vehicle for a given year if and only if the difference in rental costs (in dollars per vehicle per year) is lower or equal to avoided emissions (in tons of carbon per year per vehicle) valued at the carbon price that year (in dollars per ton).

The exponentially-increasing carbon price then influences indirectly abatement investment. In particular it does not translate into increasing abatement investment:

Proposition 1. Along the optimal path, investment is either bell-shaped or decreasing over time, and so is the optimal marginal investment cost.

Proof. See Appendix A for a formal proof. As a sketch, Eq. (9) may be re-arranged as:

$$
\forall t<T, \quad \frac{d c^{\prime}\left(x_{t}\right)}{d t}=(r+\delta) c^{\prime}\left(x_{t}\right)-\mu e^{r t}
$$

Fig. 1 plots the carbon price $\mu e^{r t}$ and two possible cases of $(r+\delta) c^{\prime}$ against time $t$. In the upper region, $(r+\delta) c^{\prime}>\mu e^{r t}$, implying that $d c^{\prime}\left(x_{t}\right) / d t>0$. In the lower region, $(r+\delta) c^{\prime}<\mu e^{r t}$, implying that $d c^{\prime}\left(x_{t}\right) / d t<0$.

The strictly decreasing profile happens for stringent climate targets, that is for high carbon prices compared to abatement 

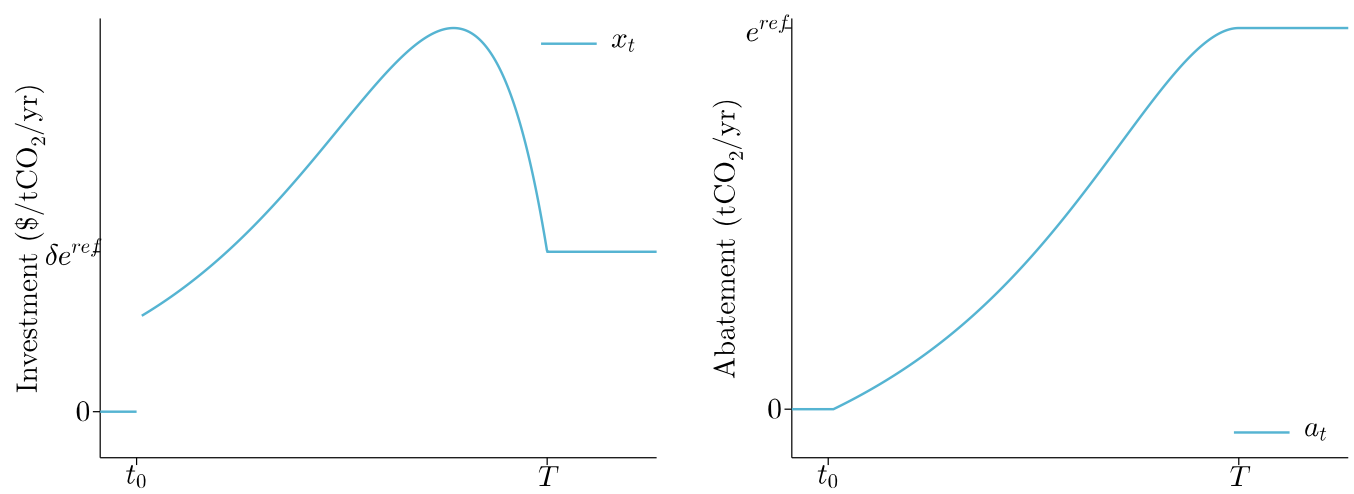

Fig. 2. Optimal timing of abatement investment and resulting abatement pathway. Left: Abatement investment is bell-shaped. Right: Abatement continuously grows over time.

investment costs $\mu>(r+\delta) c^{\prime}\left(\delta \varepsilon_{r e f}\right)$ (see Fig. 1). The bell shaped profile happens for low carbon prices or high investment costs $\mu \ll(r+\delta) c^{\prime}\left(\delta \varepsilon_{r e f}\right) .^{5}$

Prop. 1 means that taking into account two simple aspects of abatement investment - adjustment costs and finite abatement potential - in a model with a single externality - climate change in the absence of learning spillovers - is sufficient to reconcile the views that the optimal policy is a growing carbon price and that early investment is needed to stabilize climate change.

Simple calculations show that each feature separately does not provide similar results; only the combination of both adjustment costs and a maximum abatement potential leads to a transition with bell-shaped investment. If one assumes that investment costs are not strictly convex, that is $\forall x, c^{\prime}(x)=C$, then the optimal schedule is to cap all emissions in a bang bang fashion at the date $t$ when $\mu e^{r t}=(r+\delta) C$ (see also discussion in Section 6). A model without abatement potential would be unbounded and unrealistic. Without a maximum abatement potential, an exponential carbon price would result in exponentially growing investment, the total stock of abatement capital would also grow exponentially towards infinity, and emissions will decrease towards negative infinity.

Fig. 2 illustrates how such bell-shaped abatement investment translates into an increasing abatement pathway - Appendix A formally demonstrates that $a_{t}$ increases steadily to $\varepsilon_{\text {ref }}$. There is some evidence that optimal investment in long-lived capital can actually be bell-shaped. For instance, Lecocq and Shalizi (2014) report bell-shaped investment pathways in the case of the transition to nuclear power in France and the building of the national interstate highways in the United States.

\section{Optimal cost of abatement investment}

\subsection{Optimal marginal abatement investment costs}

When emission reduction requires abatement investment, the carbon price is only one of two parts of the information required to value abatement investment:

Proposition 2. Before full decarbonization, the optimal marginal cost of abatement investment $c^{\prime}\left(x_{t}\right)$ equals the sum of two terms: (1) the value of avoided emissions before the maximum abatement potential is reached; and (2) the cost of maintaining abatement capital over the long-term, after emissions have reached zero.

Proof. The solution of the differential Eq. (9) is (Appendix A):

$$
\forall t<T, \quad c^{\prime}\left(x_{t}\right)=\int_{t}^{T} \mu e^{r \theta} e^{-(\delta+r)(\theta-t)} d \theta+e^{-(\delta+r)(T-t)} c^{\prime}\left(\delta \varepsilon_{r e f}\right)
$$

In Eq. (11), emission reductions from the marginal unit of abatement capital $e^{-(\delta+r)(\theta-t)}$ are valued at the carbon price $\mu e^{r \theta}$ before $T$, and $c^{\prime}\left(\delta \varepsilon_{\text {ref }}\right)$ is the value of abatement capital at $T$.

Proposition 2 means that optimal investment in abatement capacity cannot be decided based only on the carbon price, investors have to anticipate a full decarbonization strategy. Take the example of a firm that builds cleaner personal vehicles with the intent of renting them to a taxi company facing a carbon price. When deciding how many vehicles to build at a given date, and at what cost, the manufacturer cannot rely only on the current carbon price, nor even only on the full carbon

\footnotetext{
${ }^{5}$ The threshold value corresponds to the case where $\mu=(r+\delta) c^{\prime}\left(x_{0}\right)$. Such condition is not easily linked analytically to the parameters of the model because $x_{0}$ and $\mu$ are both endogenous.
} 
price schedule. The car manufacturer has to anticipate its full investment pathway, including the date $T$ when all taxi vehicles will have been replaced by cleaner vehicles, and the cost of replacing these cleaner vehicles after $T$. In particular, the optimal cost of a new clean vehicle is not equal to the value of future avoided emissions.

The marginal abatement investment cost $c^{\prime}\left(x_{t}\right)$ represents the optimal cost of physical capital used to reduce emissions. For instance, it could be expressed in dollars per building retrofitted, or dollars per vehicle replaced with an electric vehicle. When seeing this equipment as abatement capital, one unit of capital, e.g. an electric vehicle, translates into a flux of emission reductions, e.g. $1 \mathrm{tCO}_{2} / \mathrm{yr}$. As a result, $c^{\prime}\left(x_{t}\right)$ is to be expressed in dollars per ton of avoided carbon per year $\left(\$ /\left(\mathrm{tCO}_{2} / \mathrm{yr}\right)\right)$. Because the marginal investment cost $c^{\prime}\left(x_{t}\right)$ says nothing about the lifetime of abatement capital, it does not inform directly on the amount of GHG saved thanks to a marginal investment $x_{t} d t$. An alternative metric to measure abatement investment is the levelized cost of conserved carbon, which compares investment costs to discounted committed emission reductions, as discussed in the following subsection.

\subsection{An operational metric? The levelized cost of conserved carbon}

A natural metric to measure and compare the cost of abatement investments in different options (e.g electric vehicles versus retrofitting buildings) is the ratio of (i) the cost of building and using a given option (in \$) to (ii) the discounted sum

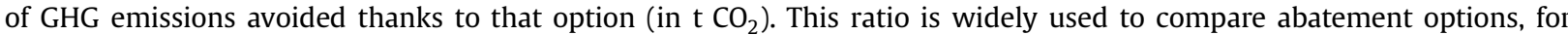
instance to build marginal abatement cost curves, and is then simply called "marginal abatement cost" (McKinsey, 2009; Vogt-Schilb and Hallegatte, 2014). The IPCC (2014a) calls this ratio the Levelized Cost of Conserved Carbon (LCCC).

Definition 1. We call Levelized Cost of Conserved Carbon (LCCC) the ratio of marginal investment costs to the corresponding discounted abatement.

The LCCC $\ell_{t}$ expresses in dollars per ton. It reads $\ell_{t}=(r+\delta) c^{\prime}\left(x_{t}\right)$ (Appendix $\left.C\right)$.

Practitioners often use the LCCC when comparing and assessing abatement investments (IPCC, 2014a), for instance replacing conventional cars with electric vehicles (EV). Assume the additional cost of an EV built at time $t$, compared to the

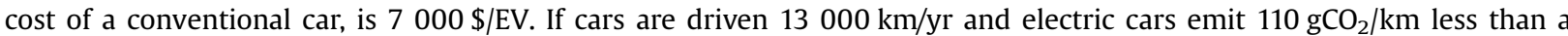
comparable internal combustion engine vehicle, each EV allows to save $1.43 \mathrm{tCO}_{2} / \mathrm{yr}$. Considering one EV is a marginal investment, the marginal abatement investment cost in this case would be $4900 \$ /\left(\mathrm{tCO}_{2} / \mathrm{yr}\right)$. If electric cars depreciate at a constant rate such that their average lifetime is 10 years $(1 / \delta=10 \mathrm{yr})$ and the discount rate is $5 \% / \mathrm{yr}$, then $r+\delta=15 \% / \mathrm{yr}$ and the $\mathrm{LCCC}$ is $730 \$ / \mathrm{tCO}_{2}{ }^{6}$

LCCCs can be expressed in the same unit as a carbon price, and, unlike the marginal rental cost of abatement capital, they fully characterize an investment pathway. ${ }^{7}$ They are a straightforward measure of abatement investment, as they relate how much is invested in the marginal unit of abatement capital to the emission reduction resulting from this marginal investment. It may thus be counter-intuitive that LCCCs should not be equal to the carbon price. As stated before, the reason is that the value of abatement investment comes from both reduced emissions and the value of abatement capital in the future Appendix D shows how an investment strategy aiming at reducing emissions without changing the future stock of abatement capital would simply equalize the marginal implicit rental cost of capital to the carbon price.

Alternatively, another way of reading (9) is:

$$
\ell_{t}=(r+\delta) c^{\prime}\left(x_{t}\right)=\mu e^{r t}+\frac{d c^{\prime}\left(x_{t}\right)}{d t}
$$

Eq. (12) means that the optimal value of abatement capital, expressed using the levelized cost of capital $\ell_{t}$, equals the carbon price $\mu e^{r t}$ plus the current variation of the value of abatement capital $\frac{d c^{\prime}\left(x_{t}\right)}{d t}$. When the value of abatement capital is increasing over time $\left(d c^{\prime}\left(x_{t}\right) / d t>0\right)$, the optimal LCCC is higher than the carbon price. This happens, if ever, at the beginning of the transition (Fig. 1). When the value of abatement capital decreases over time, the optimal LCCC is lower than the carbon price. This happen in a second phase of the transition, when the abatement potential is close to be depleted (Fig. 1).

In the following we analyze how in a multi-sector economy, the temporal evolution of the value of abatement capital differs across sectors, and thus the optimal LCCC differs across sectors.

\section{Optimal sectoral allocation of abatement investment}

In this section, we extend the model of abatement capital accumulation to investigate optimal allocation of abatement investment across sectors. The economy is partitioned in a set of sectors indexed by $i$. Each sector is described by baseline emissions, that set an abatement potential $\bar{a}_{i}$, a depreciation rate $\delta_{i}$, and a cost function $c_{i}$. For simplicity, we assume that

\footnotetext{
${ }^{6}$ The investment cost was computed as $7000 \$ /\left(1.43 \mathrm{tCO}_{2} / \mathrm{yr}\right)=4895 \$ /\left(\mathrm{tCO}_{2} / \mathrm{yr}\right)$; and the levelized cost as $0.15 \mathrm{yr}{ }^{-1} \cdot 4895 \$ /\left(\mathrm{tCO}_{2} / \mathrm{yr}\right)=734 \$ / \mathrm{tCO}_{2}$.

7 Investment $x_{t}$ can be calculated from the LCCC $\ell_{t}$ as $x_{t}=c^{\prime-1}\left(\frac{\ell_{t}}{r+\delta}\right)$. This contrasts with the rental cost of abatement capital, which defines a differential equation that has to be completed with a boundary condition to define a single investment pathway (A.12).
} 
abatement in each sector does not interact with the others. ${ }^{8}$ To make sure the problem is feasible, we assume that all emissions can be abated $\sum_{i} \bar{a}_{i}=\varepsilon_{\text {ref }}$. The maximization program becomes:

$$
\begin{array}{ll} 
& \min _{x_{i, t}} \int_{0}^{\infty} e^{-r t} \sum_{i} c_{i}\left(x_{i, t}\right) d t \\
\text { subject to } \quad \dot{a}_{i, t}=x_{i, t}-\delta_{i} a_{i, t} \quad\left(\nu_{i, t}\right) \\
a_{i, t} \leq \bar{a}_{i} \quad\left(\lambda_{i, t}\right) \\
\dot{m}_{t}=\sum_{i}\left(\bar{a}_{i}-a_{i, t}\right) \quad\left(\mu_{t}\right) \\
m_{t} \leq B \quad\left(\phi_{t}\right)
\end{array}
$$

The value of abatement capital $\nu_{i, t}$ and the cost of the sectoral potentials $\lambda_{i, t}$ now depend on the sector $i$, while there is still a single carbon price $\mu_{t}$ for the whole economy.

Similarly to the case with a single sector, the implicit rental cost in each sector is equal to the single current carbon price (see Appendix E).

$$
\forall i, \quad \forall t<T_{i}, \quad\left(r+\delta_{i}\right) c_{i}^{\prime}\left(x_{i, t}\right)-\frac{d c_{i}^{\prime}\left(x_{i, t}\right)}{d t}=\mu e^{r t}
$$

But the single implicit rental cost translates into different investment costs across sectors:

Proposition 3. Each sector $i$ is decarbonized at a different date $T_{i}$, and the optimal marginal investment cost is different in each sector:

$$
\begin{aligned}
\forall i, & \forall t<T_{i}, \\
& c_{i}^{\prime}\left(x_{i, t}\right)=\int_{t}^{T_{i}} \mu e^{r \theta} e^{-\left(\delta_{i}+r\right)(\theta-t)} d \theta+e^{-(\delta+r)\left(T_{i}-t\right)} c_{i}^{\prime}\left(\delta_{i} \bar{a}_{i}\right)
\end{aligned}
$$

Proof. Eq. (15) is the generalization of Eq. (11) to the case of several sectors (Appendix E).

In Fig. 1, the two pathways may now be seen as corresponding to two different sectors facing the same carbon price.

Which sectors should receive more investment? Loosely speaking, Eq. (15) shows that the value of abatement capital depends on the economy-wide carbon price during the transition to low-carbon capital, and then on the cost of maintaining emissions to zero in that sector. The duration of the transition $T_{i}$ and the long-run maintenance cost $c^{\prime}{ }_{i}\left(\delta_{i} \bar{a}_{i}\right)$, both depend on the sector $i$. Considering all these factors, more abatement investment should go to sectors that are more difficult to decarbonize, in the sense that they will take longer to transition to zero emissions and/or that they face a higher maintenance cost in the long run. In the following, we formally derive some conditions for a sector to be more difficult to decarbonize.

Corollary 1. Along the optimal path, investment costs are higher $(i)$ in sectors with larger abatement potential:

$$
\left(\delta_{i}=\delta_{j}, \bar{a}_{i}>\bar{a}_{j} \text { and } \forall y, c^{\prime}{ }_{i}(y)=c^{\prime}{ }_{j}(y)\right) \Longrightarrow \forall t, c_{i}^{\prime}\left(x_{i, t}\right)>c_{j}^{\prime}\left(x_{j, t}\right)
$$

and (ii) in sectors where abatement capital is nominally more expensive:

$$
\left(\delta_{i}=\delta_{j}, \quad \bar{a}_{i}=\bar{a}_{j} \text { and } \forall y, c_{i}^{\prime}(y)>c^{\prime}{ }_{j}(y)\right) \Longrightarrow \forall t, \quad c_{i}^{\prime}\left(x_{i, t}\right)>c_{j}^{\prime}\left(x_{j, t}\right)
$$

\section{Proof. See Appendix E.1.}

The intuition behind Coroll. 1 is the following. The value of abatement investment comes from avoided emissions and from the future value of abatment capital. The future value of abatement capital is greater in sectors where future investment needs are greater. These are the sectors with larger baseline emissions (as more abatement investment is then required to decarbonize them); and - maybe more surprisingly - sectors where abatement capital is more expensive, as these sectors also need to invest more money to be fully decarbonized.

Appendix E.2 relaxes the assumption that baseline emissions are constant in all sectors, and shows that the general result holds: marginal investment costs differ across sectors, and they should be higher in the sectors that are more difficult to decarbonize: those that will take longer to decarbonize, and/or those facing a higher cost of maintaining abatement capital at its maximum level.

Interestingly, the ranking established by Coroll. 1 holds when measuring marginal investment costs with the levelized cost of conserved carbon:

Corollary 2. Everything else being equal, optimal levelized costs of conserved carbon (LCCC) are higher(i) in sectors with larger abatement potential:

\footnotetext{
${ }^{8}$ This is not entirely realistic, for instance abatement realized in the power sector may actually increase the potential and reduce the cost to implement abatement in other sectors thanks to electrification (Williams et al., 2012; Audoly et al., 2017).
} 


$$
\begin{aligned}
& \delta_{i}=\delta_{j}, \bar{a}_{i}>\bar{a}_{j} \text { and } \forall y, \quad c_{i}^{\prime}(y)=c^{\prime}{ }_{j}(y) \\
\Longrightarrow & \forall t,\left(r+\delta_{i}\right) c_{i}^{\prime}\left(x_{i, t}\right)>\left(r+\delta_{j}\right) c_{j}^{\prime}\left(x_{j, t}\right)
\end{aligned}
$$

and (ii) in sectors where abatement capital is nominally more expensive:

$$
\begin{aligned}
& \delta_{i}=\delta_{j}, \quad \bar{a}_{i}=\bar{a}_{j} \text { and } \forall y, \quad c_{i}^{\prime}(y)>c^{\prime}{ }_{j}(y) \\
\Longrightarrow & \forall t, \quad\left(r+\delta_{i}\right) c_{i}^{\prime}\left(x_{i, t}\right)>\left(r+\delta_{j}\right) c_{j}^{\prime}\left(x_{j, t}\right)
\end{aligned}
$$

Proof. This corollary is a direct consequence of Coroll. 1.

Corollary 2 provides counter-intuitive policy guidance, as it suggests that more investments should be done in the sectors with higher abatement investment costs. This result is relevant when designing an abatement strategy. For instance, when abatement options are presented in a marginal abatement cost curves à la McKinsey (2009), it may be desirable to implement some of the "expensive" measures on the right-hand side of the curve, even if their LCCC is higher than the carbon price, and higher than the LCCC of alternative abatement options.

Coroll. 2 by itself does not mean that different sectors should face different carbon prices; Appendix F confirms that, in the absence of any other market failure, a single carbon price can decentralize the social optimum. If a government is able to impose the optimal carbon price schedule in a perfectly credible fashion to a well-functioning forward-looking economy, the market would perform the socially-optimal amount of abatement investment. If governments are using non-optimal policy instruments (such as sector-scale performance standards), however, or cannot commit to perfectly credible carbon price signals, Coroll. 2 suggests that second-best policy instrument need to be designed accounting for different total abatement potentials and different costs of abatement investment in different sectors (not just the shadow cost of the carbon budget $\mu$ ).

\section{Abatement investment vs. abatement cost curves}

In this section, we compare the model of abatement investment to a model based on abatement cost curves. Models of abatement cost curves are popular in the literature on the optimal timing of mitigation, and abatement cost curves are often used to frame the public debate on climate mitigation policies. Appendix G provides a very simple model based on abatement cost curves and its analytical resolution. It shows that with abatement cost curves, the optimal strategy is to equalize marginal abatement costs across sectors to the unique, exponentially-increasing carbon price. That strategy leads to increasing abatement in all sectors.

We investigate with both models the optimal cost and timing of emission reduction, at sector scale, over the 2007-2030 period. We set a policy objective over this period only, ${ }^{9}$ and use abatement cost information derived from IPCC, 2015, Fig. SPM 6. The most recent IPCC report does not feature an estimation of marginal abatement costs and potentials across sectors. Because of data limitations and of the short time horizon, this exercise is not supposed to suggest an optimal climate policy. It aims at illustrating the impact of two contrasting approaches to model emission reductions (abatement cost curves or abatement investment) on the optimal abatement strategy.

\subsection{Specification and calibration}

We calibrate the model of abatement cost curves presented in Appendix G with seven sectors of the economy: energy, industry, buildings, transport, forestry, agriculture and waste. We assume quadratic abatement costs, which grants that the abatement cost curves $\gamma_{i}$ are convex, and simplifies the resolution as marginal abatement costs are linear:

$$
\begin{aligned}
\forall i, \forall a_{i, t} \in\left[0, \bar{a}_{i}\right] \quad \gamma_{i}\left(a_{i, t}\right) & =\frac{1}{2} \gamma_{i}^{m} a_{i, t}^{2} \\
\gamma_{i}^{\prime}\left(a_{i, t}\right) & =\gamma_{i}^{m} a
\end{aligned}
$$

where $\gamma_{i}^{m}$ are parameters specific to each sector. We calibrate these using emission reductions corresponding to a $20 \$ / \mathrm{tCO}_{2}$ marginal cost in figure SPM.6 in IPCC, 2015. We calibrate the sectoral potentials $\bar{a}_{i}$ as the potential at $100 \$ / \mathrm{tCO}_{2}$ provided by the IPCC (this is the highest potential provided for each sector). Numerical values are gathered in Table 1.

To calibrate the abatement investment model, we assume quadratic investment costs:

$$
\begin{aligned}
\forall i, \forall x_{i, t} \geq 0, \quad c_{i}\left(x_{i, t}\right) & =\frac{1}{2} c_{i}^{m} x_{i, t}^{2} \\
c_{i}^{\prime}\left(x_{i, t}\right) & =c_{i}^{m} x_{i, t}
\end{aligned}
$$

To calibrate the $c_{i}^{m}$, we ensure that relative costs, when comparing two sectors, are equal in the two models, in the sense that:

\footnotetext{
${ }^{9}$ The infinite-horizon model exposed in Sections 3 has to be slightly modified; all the results exposed in the previous sections hold.
} 
Table 1

Values used in the numerical simulations.

\begin{tabular}{|c|c|c|c|c|c|}
\hline & \multirow{2}{*}{$\begin{array}{l}\text { Abatement potential } \\
\bar{a}_{i}\left[\mathrm{GtCO}_{2} / \mathrm{yr}\right]\end{array}$} & Abatement cost & \multirow{2}{*}{$\begin{array}{l}\text { Depreciation rate } \\
\delta_{i} \quad[\% / \mathrm{yr}]\end{array}$} & \multicolumn{2}{|c|}{ Investment cost } \\
\hline & & $\gamma_{i}^{m}\left[\frac{\$ / \mathrm{tCO}_{2}}{\mathrm{GtCO}_{2} / \mathrm{yr}}\right]$ & & $c_{i}^{m}$ & {$\left[\frac{\$ / \mathrm{tCO}_{2}}{\mathrm{GtCO}_{2} / \mathrm{yr}^{3}}\right]$} \\
\hline Waste & 0.76 & 34 & 3.3 & 2309 & \\
\hline Industry & 4.08 & 17.6 & 4 & 1195 & \\
\hline Forestry & 2.75 & 15.9 & 0.8 & 1080 & \\
\hline Agriculture & 4.39 & 11.9 & 5 & 808 & \\
\hline Transport & 2.1 & 11.6 & 6.7 & 788 & \\
\hline Energy & 3.68 & 10.3 & 2.5 & 699 & \\
\hline Buildings & 5.99 & 3.6 & 1.7 & 244 & \\
\hline
\end{tabular}

$$
\forall(i, j), \quad \frac{c_{i}^{m}}{c_{j}^{m}}=\frac{\gamma_{i}^{m}}{\gamma_{j}^{m}}
$$

This defines all the $c_{i}^{m}$ off by a common multiplicative constant. We calibrate this multiplicative constant such that the discounted costs of reaching the same target are equal in the two models (following Grubb et al., 1995). This way, we aim at reducing differences in optimal strategies to the different models of emission reductions (cost curves vs. investment).

We call $\bar{T}=23 \mathrm{yr}$ the time span from the publication date of IPCC, 2015 and the time horizon of IPCC data (2030). We set the discount rate to $r=4 \% / y r$. We constrain the cumulative emissions over the period as:

$$
\int_{0}^{\bar{T}} \sum_{i}\left(\bar{a}_{i}-a_{i, t}\right) \leq B
$$

To compute the carbon budget $B$, we chose the Representative Concentration Pathway RCP 8.5 (from WRI, 2015) as the emission baseline. An emission scenario consistent with the $2{ }^{\circ} \mathrm{C}$ target is the RCP3-PD. Remarkably, the difference in carbon emissions in 2030 between these two RCPs amounts to $24 \mathrm{GtCO}_{2} / \mathrm{yr}$, which matches $\sum_{i} \bar{a}_{i}$ as calibrated from IPCC (Table 1 ). We use the difference in cumulative emissions from 2007 to 2030 in the two RCPs to calibrate $B=153 \mathrm{GtCO}_{2}$.

Finally, we estimate the depreciation rates of capital as the inverse of typical capital lifetimes in the different sectors of the economy (Philibert, 2007; World Bank, 2012, Table 6.1). The resulting rates of depreciation $\delta_{i}$ are displayed in Table 1.

We solve the two models numerically in continuous time.

\subsection{Results}

Fig. 3 compares the optimal mitigation strategy by the two models and Fig. 4 compares the aggregated pathways in terms of abatement and financial effort.

The two models give the same result in the long run: abatement in each sector eventually reaches its maximum potential (Fig. 3). By construction, they also achieve the aggregated abatement target at the same discounted cost. And the carbon budget implies that the carbon price grows exponentially, regardless of how emission reductions are modeled (Fig. 3, upper panels). Moreover, the models find similar carbon prices, at $17 \$ / \mathrm{tCO}_{2}$ with cost curves and $18.6 \$ / \mathrm{tCO}_{2}$ with abatement investment - reflecting the fact that both models are calibrated on the same carbon budget and such that the total cost is equal in the two models.

However, the similar carbon prices lead to radically different strategies in terms of the temporal and sectoral distribution of aggregated abatement and costs. First, the two frameworks differ in their optimal abatement pathway: in the abatementcost-curve framework, abatement jumps when the climate policy is implemented. To emphasize this, we show in the plot that abatement equals zero between 2005 and the start of the climate policy in 2007. Such jumps, which we think are not realistic, are common in the literature on the optimal timing of mitigation (Appendix $\mathrm{G}$ ). In contrast, the abatement pathway according to the abatement-investment model starts at zero and increases continuously (Fig. 3, lower panels).

Second, the two frameworks give different results in terms of the temporal distribution of abatement costs: with abatement cost curves, abatement expenses start low and increase over time; in the abatement investment framework, abatement investment starts high and then decreases over time (Fig. 4, right). In the latter case, abatement investment is concentrated on the short term, because once all the emissions in a sector have been avoided using abatement capital, the only cost is that of maintaining the stock of abatement capital. Importantly, the appropriate level of effort that current decision makers have to implement is substantially different in the two models: 100 billion dollars of abatement expenditures versus 300 billion dollars of abatement investment. ${ }^{10}$

\footnotetext{
${ }^{10}$ Results from our abatement investment model are compatible with estimates reported by World Bank (2015), that is between 300 and 400 billion dollars per year of investment required to meet the $2{ }^{\circ} \mathrm{C}$ target, but lower than those reported by McCollum et al. (2013), at 800 billion dollars per year. Again, we do not claim that ours are optimal pathways to mitigate climate change: in particular, they only consider a target in the $2007-2030$ window. Considering the long-term objective would impose higher short-term abatement investment.
} 

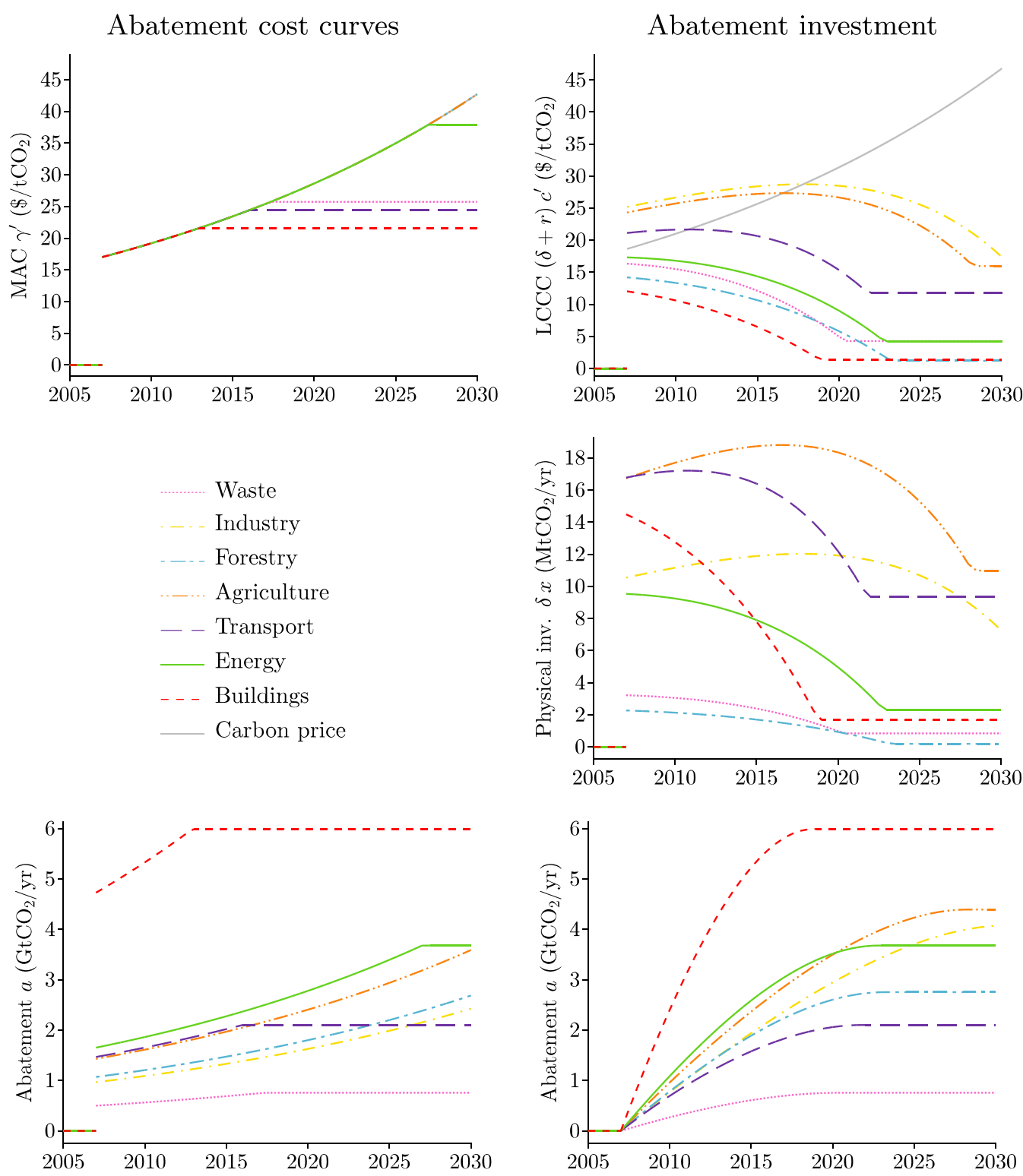

Fig. 3. Comparison of optimal abatement strategies to achieve the same amount of abatement, when the costs from IPCC (2007, SPM6) are understood in an abatement-cost-curve framework (left) vs. an abatement investment framework (right). Note: We follow Davis and Socolow (2014) in measuring investment in committed abatement, $\left(\delta_{i} x_{i, t}\right.$ in $\left.\mathrm{MtCO}_{2} / \mathrm{yr}\right)$ instead of crude investment $\left(x_{i, t}\right.$ in $\left.\mathrm{MtCO}_{2} / \mathrm{yr}{ }^{2}\right)$. With committed abatement, 1000 electric vehicles built in 2010 that will each save $11 \mathrm{tCO}_{2}$ during their lifetime count as committed abatement of $1100 \mathrm{t} \mathrm{CO} / \mathrm{yr}$ in 2010. In the abatement-costcurve framework, there is no equivalent to the physical abatement investments $x_{i, t}$, since one controls directly the abatement level $a_{i, t}$.

Third, in the abatement-cost-curve framework, the carbon price gives a straightforward indication on where and when effort should be concentrated. In contrast, the increasing carbon price is a poor indicator of the optimal distribution of abatement investment (Fig. 3, higher panels). For instance, in the abatement cost curve framework, complete decarbonization in the building sector is realized in 5 years - a somewhat unrealistic result. In the abatement investment framework, doing so would imply a very high level of investment in building retrofit, and therefore very high investment costs. As a result, the model with abatement investment smooths these investments over 12 years, to reduce the overall cost of decarbonizing the building sector.

Since costs differ across sectors, this smoothing mechanism is different across sectors, leading to different marginal abatement investment costs and different levelized costs of conserved carbon (LCCC) across sectors. For instance, in this numerical example, the optimal short-term LCCC is twice as high in the industrial sector as in the building sector even if the climate policy is implemented with a single carbon price. Facing an abatement option that costs $25 \$ / \mathrm{tCO}_{2}$ in the industrial sector and an abatement option at $15 \$ / \mathrm{tCO}_{2}$ in the building sector, the optimal choice is to invest in the former, not in the 

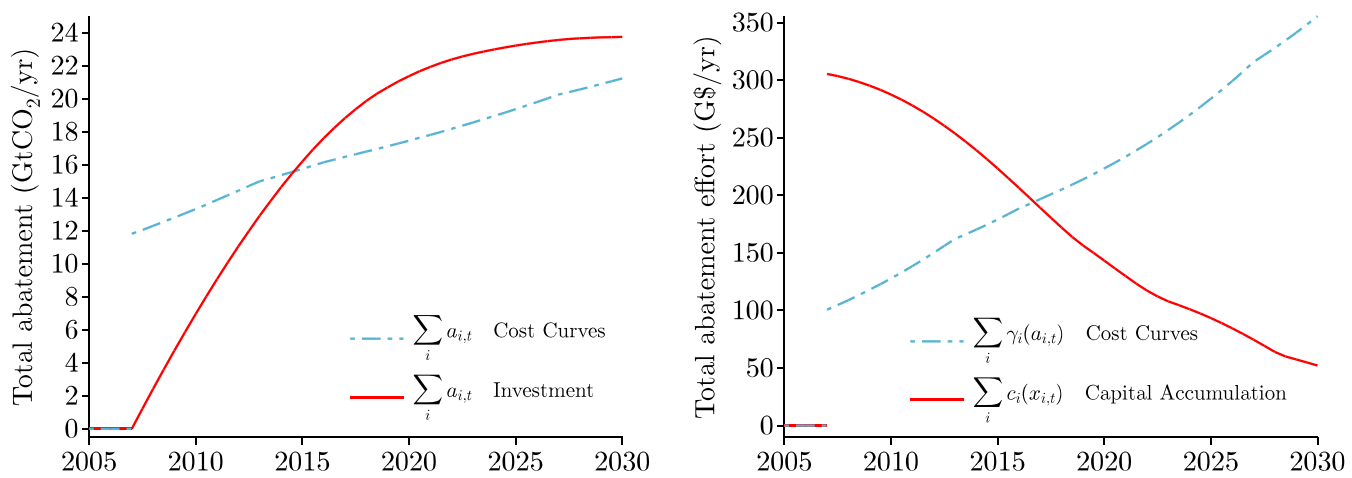

Fig. 4. Optimal timing and cost of GHG emission reductions in the two models (abatement cost curves vs abatement capital accumulation). When abatement is assumed to be freely chosen on a cost curve at each time step, the abatement can jump to any amount instantaneously at the beginning of the period. When abatement requires accumulating capital, abatement has to grow continuously. The same carbon price (not shown) translates in radically different short-term expenses in the two models (right panel).

latter. Notice that in the abatement investment sector, sectors are ranked differently at any moment $t$, depending on whether one looks at expenses, investment, or abatement.

How much to smooth costs depends critically on the severity of adjustment costs. In the working paper version of this article (Vogt-Schilb et al., 2012), we study the role of convexity of the investment cost function on the optimal emission pathway, using a generic power function instead of assuming quadratic investment costs. The more convex the function, the more the social planner spreads abatement investment over time. If costs are not convex at all, that is $\forall x_{i}, c^{\prime}{ }_{i}\left(x_{i}\right)=C$, then the sector $i$ is decarbonized instantaneously at the date $t_{i}$ such that $\mu e^{r t_{i}}=\left(r+\delta_{i}\right) C$ (which is not realistic as economies cannot switch overnight to zero carbon capital). With no adjustment costs, the abatement investment model gives results similar to those that would emerge from an abatement cost model with a stepwise abatement cost curve.

This numerical application illustrates that using the levelized cost of conserved carbon to compare abatement investment across sectors can be misleading. It also suggests using abatement cost curves with caution, in particular when assessing options that involve investment in long-lived capital. (Symmetrically, the abatement-investment model proposed here should not be used to assess measures, such as driving less miles per year or reducing air conditioning, that are best modelled using abatement cost curves.) Finally, it shows that discussing the optimal timing of emission reduction by discussing abatement curves and the time profile of the shadow cost of carbon might send the wrong message to policymakers. $^{11}$

\section{Conclusion}

Two types of emission-reduction actions should be distinguished to investigate when and where to reduce greenhouse gases emissions. In every sector of the economy, some actions bring immediate and short-lived environmental benefits, such as driving fewer miles per year, using existing gas power plants more hours per year and existing coal power plants fewer hours per year, or reducing air conditioning. These are appropriately modeled with abatement cost curves. For these actions, the increasing carbon price provides direct guidance on where and when effort to reduce emissions should be allocated.

But in every sector, many actions imply one-time investment and persistent emission reductions over a long period of time - such as replacing gasoline vehicles with plug-in hybrid or electric vehicles, replacing fossil-fueled power plants with renewable power, or retrofitting buildings. These are best modeled as abatement investment. In these cases, decision-makers have control over the rate of change of emission reductions, rather than the emission level directly. For these actions, the carbon price does not provide a direct indication of the optimal distribution of emission reductions over time and across sectors; one must also take into account the future value of abatement capital when assessing abatement investment. An increasing carbon price translates into optimal abatement investment that can be bell-shaped or concentrated over the

11 Yet this practice is common in the literature. Many papers expand the DICE framework to investigate the impact of particular aspects of the climateeconomy system on the optimal timing of climate mitigation. Examples include Kolstad (1996) and Keller et al. (2004) on learning that reduces climate uncertainty over time; Bruin et al. (2009) and Bosello et al. (2010) on how considering adaptation to climate change impacts may affect optimal mitigation; Hwang et al. (2013) and Lemoine and Traeger (2014) on the impact of fat-tailed risks and the role of tipping points; and Heal and Millner (2014) on the choice of the appropriate discount rate for climate policy. Dietz and Stern (2014) propose several modifications to DICE, including the use of a lower discount rate, and a different modelling of climate-change-related damages. All these papers study the optimal timing of GHG reductions, and in all of them the question boils down to the question of the optimal carbon price schedule.

Similarly, Jacoby and Sue Wing (1999), van der Zwaan et al. (2002), Fischer et al. (2004) and Williams (2010) all have models featuring investment in abatement capital. They all present their results in terms of the carbon price schedule, or the resulting value of abatement capital, without discussing the implications for immediate investment needs. Finally, a literature on the optimal distribution of effort across sectors focuses on pinning down sectorspecific market or government failures that would justify different carbon prices in different sectors (e.g., Hoel, 1996; Rosendahl, 2004). 
short run. Moreover, more investment per abated ton is needed in sectors with larger abatement potentials and in sectors where abatement capital is more expensive, even though the same carbon price applies to all sectors. For instance, we find in an illustrative example that an abatement option at $25 \$ / \mathrm{tCO}_{2}$ in the industrial sector can be preferable to a $15 \$ / \mathrm{tCO}$ option in the building sector.

These results suggest that when assessing abatement investment, the ratio of marginal investment costs to discounted abatement is a poor indicator of where abatement investment should be concentrated - such ratio, sometimes labeled the levelized cost of conserved carbon or misleadingly marginal abatement cost, is however broadly used in the policy debate to compare abatement options, for instance in marginal abatement cost curves a la McKinsey (2009). Our results also suggest that the dynamics of abatement capital accumulation cannot be represented with abatement cost curves. It can thus be misleading to use models based solely on abatement cost curves to design or assess abatement strategies, or to investigate the optimal timing or distribution across sectors of abatement effort.

In terms of policy design, a perfectly credible carbon price imposed to a well-functioning forward-looking market would in principle trigger the socially-optimal abatement investment. In practice, while some governments have implemented carbon prices, no existing carbon price is scheduled to grow automatically over the long term (World Bank, 2014). ${ }^{12}$ Part of the reason could be that governments have limited ability to commit credibly to future carbon prices (Brunner et al., 2012). In addition, many existing climate policies, such as feed-in-tariffs, renewable portfolio mandates, feebates, and performance standards, are implemented at the sector scale (IEA, 2015) - and many of them directly incentivize or mandate investment in clean capital, thus not requiring the government to commit to future carbon prices.

Our results suggest that such policies should be evaluated with care. Second-best sector-specific policies depend on both the abatement potential and the cost of abatement investment in each sector, in addition to the carbon price. If the mechanisms highlighted in this paper are disregarded, well-designed sector-scale policies would thus appear to impose excessive costs in the short term, especially in the sectors that are difficult to decarbonize.

\section{Acknowledgments}

We thank Alain Ayong Le Kama, Mook Bangalore, Patrice Dumas, Marianne Fay, Michael Hanemann, Frédéric Ghersi, Louis-Gatan Giraudet, Christian Gollier, Christophe de Gouvello, Céline Guivarch, Jean Charles Hourcade, Tamaro Kane, Oskar Lecuyer, Baptiste Perissin Fabert, Antonin Pottier, Lionel Ragot, Julie Rozenberg, François Salanié, Ankur Shah, Nicolas Stern, Mike Toman, several anonymous referees, seminar participants at Cired, École Polytechnique, Université Paris Ouest, Paris Sorbonne, Toulouse School of Economics, Princeton University's Woodrow Wilson School, the Joint World Bank - International Monetary Fund Seminar on Environment and Energy Topics, the Conference on Pricing Climate Risk held at Center for Environmental Economics and Sustainability Policy of Arizona State University, and audiences at the EAERE and the ASSA and SURED conferences for useful comments and suggestions on various versions of this paper. The remaining errors are the authors' responsibility. We acknowledge financial support from Institut pour la Mobilité Durable (Renault and ParisTech), ESMAP (The World Bank), and the Chaire Développement Durable École Polytechnique-EDF. The views expressed in this paper are the sole responsibility of the authors. They do not necessarily reflect the views of the Inter-American Development Bank, the World Bank, their executive directors, or the countries they represent.

\section{Appendix A. Optimal accumulation of abatement capital}

\section{A.1. Hamiltonian}

The Hamiltonian associated with (6) reads:

$$
H\left(x_{t}, a_{t}, m_{t}\right)=e^{-r t}\left(c\left(x_{t}\right)+\lambda_{t}\left(a_{t}-\varepsilon_{r e f}\right)+\nu_{t}\left(\delta a_{t}-x_{t}\right)+\mu_{t}\left(\varepsilon_{r e f}-a_{t}\right)+\phi_{t}\left(m_{t}-B\right)\right)
$$

\section{A.2. First order conditions}

The first order conditions read:

$$
\frac{\partial H}{\partial x_{t}}=0 \Longleftrightarrow c^{\prime}\left(x_{t}\right)=\nu_{t}
$$

\footnotetext{
${ }^{12}$ For instance, the British Columbia carbon tax was phased-in, increasing from 10 to $30 \mathrm{C} \$ / \mathrm{tCO}_{2}$ between 2008 and 2012 , but is currently not scheduled to increase any more (Ministry, 2015). The European carbon market sets a cap over a few years (the current phase runs until 2020), but optimal abatement investment in long-lived capital such as power plants would require allowances to be credibly announced several decades in advance. Similarly, the French carbon tax is scheduled to increase from 14.5 Euros per ton in 2015 to 100 Euros per ton in 2030, but no further increase is scheduled.
} 


$$
\begin{aligned}
& \frac{\partial H}{\partial a_{t}}-\frac{d\left(e^{-r t} \nu_{t}\right)}{d t}=0 \Longleftrightarrow \dot{\nu}_{t}-(\delta+r) \nu_{t}=\lambda_{t}-\mu_{t} \\
& \frac{\partial H}{\partial m}+\frac{d\left(e^{-r t} \mu_{t}\right)}{d t}=0 \Longleftrightarrow \dot{\mu}_{t}-r \mu_{t}=-\phi_{t}
\end{aligned}
$$

Where $\nu_{t}$ is the current value of abatement capital, $\mu$ is the current cost of carbon, and $\lambda_{t}$ is the current social cost of the maximum abatement potential. ${ }^{13}$

Eqs. (A.3) and (A.2) can be rearranged as:

$$
(r+\delta) c^{\prime}\left(x_{t}\right)-\frac{d c^{\prime}\left(x_{t}\right)}{d t}=\left(\mu_{t}-\lambda_{t}\right)
$$

\section{A.3. Complementary slackness conditions}

The following complementary slackness condition implies that the carbon price grows at the discount rate before the steady state:

$$
\begin{gathered}
\forall t, \quad \phi_{t}\left(B-m_{t}\right)=0 \\
m_{t}<B \Longrightarrow \mu_{t}=\mu e^{r t} \quad \text { (from Eq. (A.4)) }
\end{gathered}
$$

Eq. (A.6) is similar to a Hotelling rule: here, the carbon budget is analogous to a nonrenewable resource. The other complementary slackness conditions is

$$
\forall t, \quad\left(a_{t}-\varepsilon_{r e f}\right) \lambda_{t}=0
$$

\section{A.4. Steady state}

We call $T$ the date when the carbon budget is reached. After $T$, emission are nill and investment is used to counterbalance depreciation:

$$
\forall t \geq T, \quad \dot{m}_{t}=0 \Longrightarrow a_{t}=\varepsilon_{r e f} \Longrightarrow x_{t}=\delta \varepsilon_{r e f}
$$

\section{A.5. The optimal temporal profile of abatement and investment}

In this subsection, we show that along the optimal trajectory, abatement capital increases over time before $T$; and that optimal investment is either bell-shaped or decreasing with respect to time and so is the marginal investment cost, even though the carbon price is exponentially increasing. We first show that

Lemma 1. if $a_{t}<e_{\text {ref }}$ then $x_{t}$ is either decreasing or increasing then decreasing,

then we show that

Lemma 2. $a_{t}$ is increasing and is strictly lower than $e_{\text {ref }}$ before the finite date $T$.

Lemma 1 formalizes one of the main messages from this paper: a growing carbon price does not translate into growing abatement investment. Lemma 2 reflects that since the only reason to invest in abatement is to reach the carbon budget, it cannot be optimal to abate all emissions before the date when the carbon budget is reached.

Proof. - Lemma 1 If $a_{t}<e_{\text {ref }}$, Eq. (A.5) may be re-arranged as:

$$
\forall t \text { s. t. } a_{t}<\varepsilon_{r e f}, \quad \frac{d c^{\prime}\left(x_{t}\right)}{d t}=(r+\delta) c^{\prime}\left(x_{t}\right)-\mu e^{r t}
$$

Fig. 1 shows that (A.9) results in Lemma 1. Here we also provide a formal proof. First, notice that since $\frac{d c^{\prime}\left(x_{t}\right)}{d t}=\dot{x}_{t} \frac{d^{2} c(x)}{d x^{2}}$ and we assume that $c$ is strictly convex, investment $x_{t}$ and marginal investment costs $c^{\prime}\left(x_{t}\right)$ have the same temporal evolution. Eq. (A.9) implies that if optimal investment is decreasing at a date $\theta$, it continues to decrease $\forall t>\theta$ s. t. $a_{t}<\varepsilon_{\text {ref }}$. Indeed $\frac{d c^{\prime}\left(x_{t}\right)}{d t}<0 \Longrightarrow(r+\delta) c^{\prime}\left(x_{\theta}\right)<\mu e^{r \theta}$. In that case, $c^{\prime}\left(x_{\theta}\right)$ decreases over time, and $\mu e^{r \theta}$ always increases over time, so that

\footnotetext{
${ }^{13}$ Note that the FOCs do not depend on $\varepsilon_{\text {ref }}$, showing that the assumption that $\varepsilon_{\text {ref }}$ is constant over time does not impact the basic dynamics of the model.
} 
$(r+\delta) c^{\prime}\left(x_{\theta}\right)$ remains lower than $\mu e^{r \theta}$ and $\frac{d c^{\prime}\left(x_{t}\right)}{d t}$ remains lower than 0.

Now consider the case where $c^{\prime}\left(x_{t}\right)$ is increasing. In that case, it cannot increase indefinitely. Since $\frac{d c^{\prime}\left(x_{t}\right)}{d t}>0 \Longrightarrow(r+\delta) c^{\prime}\left(x_{t}\right)>\mu e^{r t}$. Ever increasing investment would thus lead to infinite abatement capital, higher than $\varepsilon_{r e f}$. This means that if $c^{\prime}\left(x_{t}\right)$ increases over time, then there is a $\theta$ such that investment stop increasing, that is $\frac{d c^{\prime}\left(x_{t}\right)}{d t}=0$. Deriving (A.9) with respect to time shows that $\frac{d c^{\prime}\left(x_{t}\right)}{d t}=0 \Longrightarrow \frac{d^{2} c^{\prime}\left(x_{t}\right)}{d t^{2}}<0$, meaning $c^{\prime}$ has reached its maximum at $\theta$ Immediately after $\theta, c^{\prime}$ starts decreasing.

Summarizing, if investment starts decreasing, it will decrease as long as A.9 holds, and if is starts increasing, it will eventually cross the carbon price, and decrease afterward as long as A.9 holds. (Fig. 1).

- Lemma 2 Let us now show that $a_{t}$ is increasing $\forall t<T$. First, note that $a_{t}$ starts from 0 and is necessarily increasing at first. Second, if $a_{t}$ is not continuously increasing, then there is a date $t$ such that $\dot{a}_{t}=0$ and $\ddot{a}_{t} \leq 0$. Then, at this date $\dot{a}_{t}=x_{t}-\delta a_{t}$ and $\ddot{a}_{t}=\dot{x}_{t}-\delta \dot{a}_{t}=\dot{x}_{t}$, so $\dot{x}_{t} \leq 0$ and $x_{t}$ decreases for all future dates (Lemma 1 ). This implies that $a_{t}$ also decreases at all future dates (otherwise, reproducing the reasoning would give a date $\tau>t$ with $\dot{x}_{\tau} \geq 0$ ), and $m_{t}$ ends up above $B$, a contradiction. $a_{t}$ is thus steadily increasing over time. A direct consequence is that $\forall t<T, a_{t}<\varepsilon_{\text {ref }}$. Finally, let us show that abatement reaches its potential in finite time, $T<+\infty$ : otherwise (A.9) is satisfied at all dates, and

$$
c^{\prime}\left(x_{t}\right)=c^{\prime}\left(x_{0}\right) e^{(r+\delta) t}-\frac{\mu e^{r t}}{\delta}\left(e^{\delta t}-1\right)
$$

which tends either to $+\infty$ or $-\infty$, a contradiction.

Since emissions equal zero after $T$ and strictly positive before, the social cost of the maximum potential is also zero before the steady state:

$$
\begin{aligned}
& \forall t<T, a_{t}<\varepsilon_{\text {ref }} \text { and } \lambda_{t}=0 \\
& \forall t \geq T, a_{t}=\varepsilon_{\text {ref }} \text { and } \lambda_{t} \geq 0
\end{aligned}
$$

\section{A.6. Solving for $c^{\prime}$}

Before $T,($ A.10) allows simplifying (A.5) to:

$$
\forall t<T, \quad(r+\delta) c^{\prime}\left(x_{t}\right)-\frac{d c^{\prime}\left(x_{t}\right)}{d t}=\mu e^{r t}
$$

The solutions of this first order linear differential equation read:

$$
\forall t<T, \quad C^{\prime}\left(x_{t}\right)=e^{(r+\delta) t} \int_{t}^{T} e^{-(r+\delta) \theta} \mu e^{r \theta} d \theta+e^{(r+\delta) t} C
$$

Where $C$ is a constant. Any $C$ defines an investment pathway that is consistent with the exponentially growing carbon price (A.11). The optimal investment pathways also satisfies a boundary condition: the full potential must be reached at the date $T$.

\section{A.7. Boundary conditions}

After $T, a_{t}$ is constant and the investment $x_{t}$ is used to counterbalance the depreciation of abatement capital.

$$
c^{\prime}\left(x_{T}\right)=c^{\prime}\left(\delta \varepsilon_{\text {ref }}\right) \quad(\text { from Eq. A.8) }
$$

\section{A.8. Optimal marginal investment costs (MICs)}

Injecting (A.13) in (A.12) and re-arranging, one gets:

$$
\begin{aligned}
& \forall t<T, \\
& C^{\prime}\left(x_{t}\right)=\mu e^{r t} \int_{t}^{T} e^{-\delta(\theta-t)} d \theta+e^{-(\delta+r)(T-t)} C^{\prime}\left(\delta \varepsilon_{r e f}\right)
\end{aligned}
$$

which can also be written as:

$$
c^{\prime}\left(x_{t}\right)=\int_{t}^{T} \mu e^{r \theta} e^{-(\delta+r)(\theta-t)} d \theta+\int_{T}^{\infty}(r+\delta) c^{\prime}\left(\delta \varepsilon_{r e f}\right) e^{-(\delta+r)(\theta-t)} d \theta
$$

In Eq. (A.15), output from the marginal, deprecating, abatement capital is valued at the current carbon price before $T$, and 
valued at the replacement cost of abatement capital $c^{\prime}\left(\delta \varepsilon_{\text {ref }}\right)$ after $T .^{14}$

\section{A.9. The forgone-opportunity effect}

Here we explain how the previous result compares to Slechten (2013). Eq. (A.15)can be rewritten to show that the marginal abatement investment cost $c^{\prime}\left(x_{t}\right)$ can be expressed as the sum of three terms: (1) the value $\mathcal{E}$ of avoided emissions along the full lifetime of the investment; (2) the value $O$ of the forgone opportunity, since each investment in abatement capital reduces future investment opportunities; and (3) the value $\mathcal{K}$ of abatement capital in the long run:

$$
\begin{aligned}
& \forall t<T, \quad c^{\prime}\left(x_{t}\right)=\underbrace{\mu e^{r t} \int_{t}^{\infty} e^{-\delta(\theta-t)} d \theta}_{\mathcal{E}}-\underbrace{\mu e^{r t} \int_{T}^{\infty} e^{-\delta(\theta-t)} d \theta}_{O} \\
& +\underbrace{e^{-(r+\delta)(T-t)} c^{\prime}\left(\delta \varepsilon_{r e f}\right)}_{\mathcal{K}}
\end{aligned}
$$

The second term $O$ echoes previous findings by Slechten, 2013 and can be interpreted as a forgone-opportunity effect. The limited potential $\varepsilon_{\text {ref }}$ behaves here like a non-renewable resource, an abatement deposit. After $T$, accumulating more abatement capital does not allow to reduce emissions. The value $O$ of this forgone opportunity is the value of the GHG that the maximum potential prevents to save after $T$. Slechten (2013) does not have an analog to $\mathcal{K}$ as she neglects depreciation.

\section{Appendix B. Optimal investment dynamics are similar under cost-effectiveness and cost-benefit}

Here, we clarify that the results exposed in the previous section do not depend on the fact that we used a cost-effectiveness analysis instead of a cost-benefit analysis.

Consider the following problem, where a social planner minimizes the sum of abatement investment costs and the cost of climate change impacts:

$$
\begin{array}{ll}
\min _{x_{t}} \int_{0}^{8} e^{-r t}\left(c\left(x_{t}\right)+d\left(m_{t}\right)\right) d t & \\
\text { subject to } \dot{m}_{t}=e_{r e f}-a_{t} & \left(\mu_{t}\right) \\
\dot{a}_{t}=x_{t}-d a_{t} & \left(\nu_{t}\right) \\
a_{t}=e_{\text {ref }} & \left(\lambda_{t}\right)
\end{array}
$$

Where $d\left(m_{t}\right)$ is an increasing and convex function that captures damages from climate change impacts.

The Hamiltonian associated with (B.1) reads:

$$
H\left(x_{t}, a_{t}, m_{t}\right)=e^{-r t}\left(c\left(x_{t}\right)+d\left(m_{t}\right)+\lambda_{t}\left(a_{t}-e_{r e f}\right)+\nu_{t}\left(d a_{t}-x_{t}\right)+\mu_{t}\left(e_{r e f}-a_{t}\right)\right)
$$

The first order conditions read:

$$
\begin{aligned}
& \frac{\partial H}{\partial x_{t}}=0 \Longleftrightarrow c^{\prime}\left(x_{t}\right)=\nu_{t} \\
& \frac{\partial H}{\partial a_{t}}-\frac{d\left(e^{-r t} \nu_{t}\right)}{d t}=0 \Longleftrightarrow \dot{\nu}_{t}-(\delta+r) \nu_{t}=\lambda_{t}-\mu_{t} \\
& \frac{\partial H}{\partial m}+\frac{d\left(e^{-r t} \mu_{t}\right)}{d t}=0 \Longleftrightarrow \dot{\mu}_{t}=r \mu_{t}-d^{\prime}\left(m_{t}\right)
\end{aligned}
$$

Compared to the case of a carbon budget, the optimal carbon price is now more complex, and cannot be expressed analytically in general. Fischer et al. (2004) study the possible temporal profiles of the carbon price resulting from (E.4). In the case relevant to this paper, the optimal carbon price first increases over time and then tends to a constant value at the steady state, once GHG concentration in the atmosphere have stabilized at an endogenous level $B^{\star}$ (see Figures. 2 and 3 in Fischer et al., 2004).

In this paper, we focus on how the carbon price translates to optimal abatement investment (and how optimal investment differs across sectors). Irrespective of the particular shape of the carbon price, it remains the case that before the

\footnotetext{
${ }^{14} c^{\prime}\left(\delta \varepsilon_{r e f}\right)$ is the replacement cost of the capital after $T$. It is the cost one has to pay to buy one unit of abatement capital and keep it for its lifetime. $(r+\delta) c^{\prime}\left(\delta \varepsilon_{\text {ref }}\right)$ is the corresponding rental cost, since $d c^{\prime}\left(x_{t}\right) / d t=0$ after $T$. It is the price one has to pay for renting abatement capital for one unit of time.
} 
steady state, emissions are positive, $\lambda_{t}=0$, and B.3 and B.4 can be integrated so as to express optimal investment as a function of the carbon price $\mu_{t}$ as:

$$
\begin{aligned}
& \forall t \leq T \\
& C^{\prime}\left(x_{t}\right)=\int_{t}^{T} \mu_{\theta} e^{-(\delta+r)(\theta-t)} d \theta+\int_{T}^{\infty}(r+\delta) c^{\prime}\left(\delta \varepsilon_{r e f}\right) e^{-(\delta+r)(\theta-t)} d \theta
\end{aligned}
$$

In particular, Prop. 2 holds (as does Coroll. 2).

Yet another equivalent problem is the following, where a social planner (or any equivalent decentralized procedure) faces an exogenous carbon price $\mu_{t}$ on unabated emissions:

$$
\begin{array}{ll}
\min _{x_{t}} \int_{0}^{8} e^{-r t}\left(c\left(x_{t}\right)+\mu_{t}\left(e_{r e f}-a_{t}\right)\right) d t & \\
\text { subject to } \dot{a}_{t}=x_{t}-d a_{t} & \left(\nu_{t}\right) \\
a_{t}=e_{\text {ref }} & \left(\lambda_{t}\right)
\end{array}
$$

This problem also leads to optimal marginal abatement investment costs to be valued at the carbon price before the steady state, and at the replacement cost of abatement capital after the steady state - that is, (B.6) and Prop. 2 (and Coroll. 2) all remain true.

\section{Appendix C. Proof of the expression of the LCCC $\theta_{t}$}

Let $h$ be a marginal physical investment in abatement capital made at time $t$ in sector $i$ (expressed in tCO $2 / \mathrm{yr}$ per year). It generates an infinitesimal abatement flux that starts at $h$ at time $t$ and decreases exponentially at rate $\delta_{i}$, leading to discounted abatement $\Delta A$ (expressed in $\mathrm{tCO}_{2}$ ):

$$
\begin{aligned}
\Delta A & =\int_{\theta=t}^{\infty} e^{r(\theta-t)} h e^{-\delta_{i}(\theta-t)} d \theta \\
& =\frac{h}{r+\delta}
\end{aligned}
$$

This additional investment $h$ brings current investment from $x_{t}$ to $\left(x_{t}+h\right)$. The additional cost $\Delta C$ (expressed in $\$$ ) that it brings reads:

$$
\Delta C=c\left(x_{t}+h\right)-c\left(x_{t}\right) \underset{h \rightarrow 0}{=} h c^{\prime}\left(x_{t}\right)
$$

The levelized cost of conserved carbon $\ell_{t}$ is the ratio of additional costs by additional discounted abatement:

$$
\begin{aligned}
& \ell_{t}=\frac{\Delta C}{\Delta A} \\
& \ell_{t}=(r+\delta) c^{\prime}\left(x_{t}\right)
\end{aligned}
$$

\section{Appendix D. An alternative understanding of the marginal implicit rental cost of abatement capital}

From an existing investment pathway $\left(x_{t}\right)$ leading to an abatement pathway $\left(a_{t}\right)$, the social planner may increase investment by one unit at time $\theta$ and immediately reduce investment by $1-\delta d \theta$ at the next period $\theta+d \theta$. The resulting investment schedule $\left(\tilde{x}_{t}\right)$ leads to an abatement pathway $\left(\tilde{a}_{t}\right)$ that abates one supplementary unit of GHG between $\theta$ and $\theta+d \theta$ (Fig. D.5). Moving from $\left(x_{t}\right)$ to $\left(\tilde{x}_{t}\right)$ costs:

$$
\mathcal{P}=\frac{1}{d \theta}\left[c^{\prime}\left(x_{\theta}\right)-\frac{(1-\delta d \theta)}{(1+r d \theta)} c^{\prime}\left(x_{\theta+d \theta}\right)\right]
$$

For marginal time lapses, this tends to:

$$
\mathcal{P} \underset{d \theta \rightarrow 0}{\longrightarrow}(r+\delta) c^{\prime}\left(x_{\theta}\right)-\frac{d c^{\prime}\left(x_{\theta}\right)}{d \theta}
$$

$\mathcal{P}$ tends to the cost of renting one unit of abatement capital at $\theta$. 

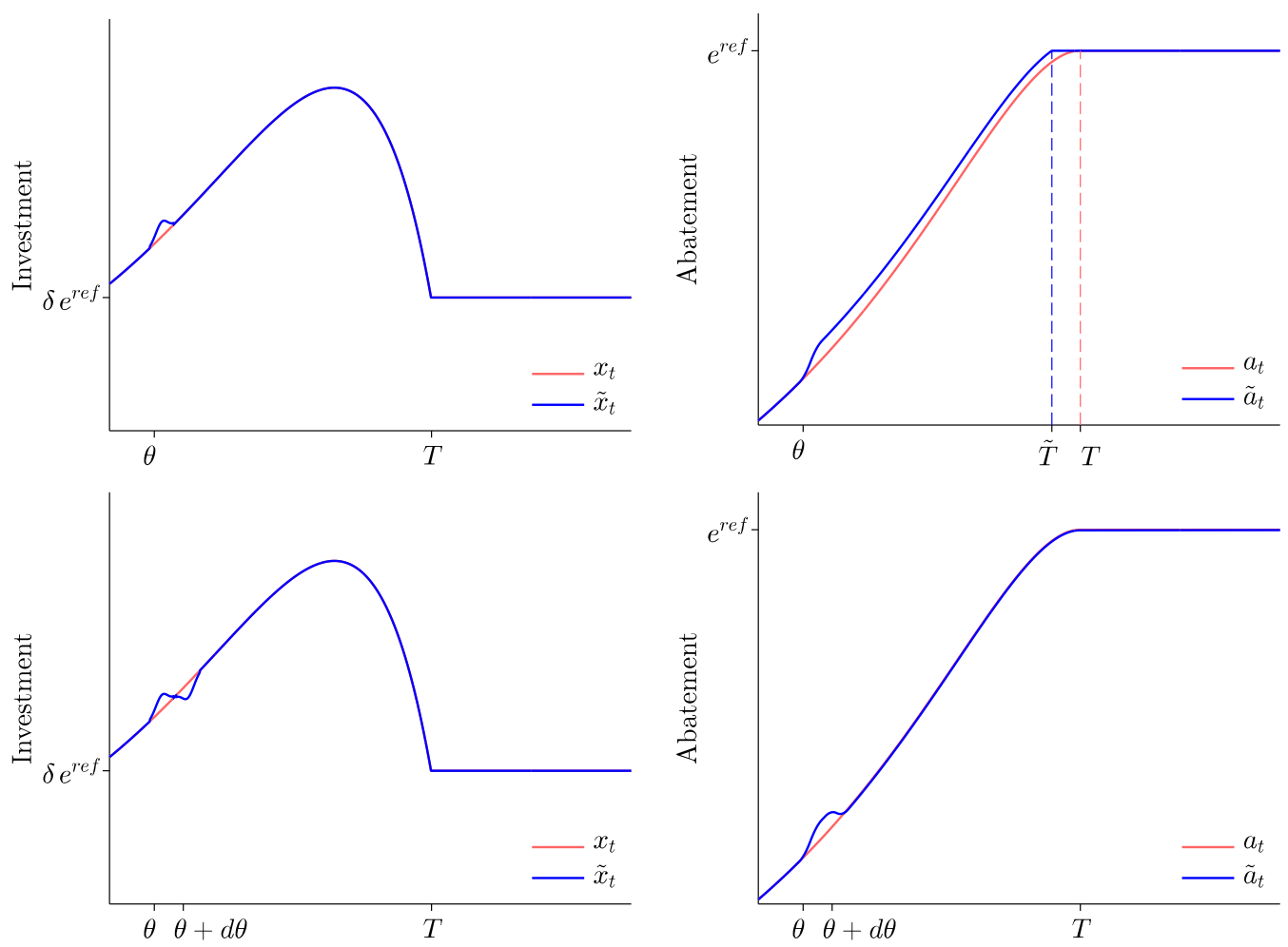

Fig. D.5. Top row: from a given investment pathway $\left(x_{t}\right)$ leading to the abatement pathway $\left(a_{t}\right)$, one additional unit of investment at time $\theta$ has two effects: it saves GHG, and brings forward the date when the maximum potential $\varepsilon_{\text {ref }}$ is reached $(T \rightarrow \tilde{T})$. Bottom row: saving one more unit of GHG at a date $\theta$ without changing the rest of the abatement pathway, as in $\left(\tilde{a}_{t}\right)$, requires to invest one more unit at $\theta$ and $(1-\delta d \theta)$ less at $\theta+d \theta$, as $\left(\tilde{x}_{t}\right)$ does.

\section{Appendix E. Optimal allocation of abatement investment}

The Hamiltonian associated with (13) reads:

$$
\begin{aligned}
H\left(x_{i, t}, a_{i, t}, m_{t}\right)= & e^{-r t}\left(\sum_{i} c_{i}\left(x_{i, t}\right)+\sum_{i} \lambda_{i, t}\left(a_{i, t}-\bar{a}_{i}\right)+\sum_{i} \nu_{i, t}\left(\delta_{i} a_{i, t}-x_{t}\right)\right. \\
& \left.+\mu_{t} \sum_{i}\left(\bar{a}_{i}-a_{i, t}\right)+\phi_{t}\left(m_{t}-B\right)\right)
\end{aligned}
$$

The first order conditions read $\forall(i, t)$ :

$$
\begin{aligned}
& c_{i}^{\prime}\left(x_{i, t}\right)=\nu_{i, t} \quad\left(\partial x_{i, t}\right) \\
& \dot{\nu}_{i, t}-\left(\delta_{i}+r\right) \nu_{i, t}=\lambda_{i, t}-\mu_{t} \quad\left(\partial a_{i, t}\right) \\
& \dot{\mu}_{t}-r_{\mu_{t}}=-\phi_{t} \quad\left(\partial m_{t}\right)
\end{aligned}
$$

Where $\nu_{i, t}$ is the present value of investment in low carbon capital, $\mu$ is the present cost of carbon, and $\lambda_{i, t}$ is the social cost of the sectoral potential. The steady state is reached at a date $T_{m}$ when the carbon budget is reached. After this date, emissions equal zero in every sector and investment is used to counterbalance depreciation:

$$
\dot{m}_{t}=0 \Longrightarrow \forall i, a_{i, t}=\bar{a}_{i} \Longrightarrow x_{i, t}=\delta_{i} \bar{a}_{i}
$$

Denoting $T_{i}$ the date when all emissions in sector $i$ are capped $\left(\forall i \geq T_{i}, a_{i, t}=\bar{a}_{i}\right)$, it is easy to establish that $T_{m}=\max _{i}\left(T_{i}\right)$ (adapting the resolution from Appendix A). The complementary slackness conditions mean that the carbon price grows at the discount rate before the steady state:

$$
\forall t<T_{m}, m_{t}<B \text { and } \phi_{t}=0
$$




$$
\Longrightarrow \mu_{t}=\mu e^{r t}
$$

and the social costs of the sectoral potentials are zero before the respective dates $T_{i}$ :

$$
\forall t<T_{i}, a_{i, t}<\bar{a}_{i} \text { and } \lambda_{i, t}=0
$$

The first order conditions can be re-arranged as:

$$
\forall(i, t), \quad\left(r+\delta_{i}\right) c_{i}^{\prime}\left(x_{i, t}\right)-\frac{d c_{i}^{\prime}\left(x_{i, t}\right)}{d t}=\mu e^{r t}-\lambda_{i, t}
$$

Following the demonstration for the case of one single sector (Appendix A) yields:

$$
\begin{aligned}
c_{i}^{\prime}\left(x_{i, t}\right) & =\mu e^{r t} \int_{t}^{T_{i}} e^{-\delta_{i}(\theta-t)} d \theta+e^{-(\delta+r)\left(T_{i}-t\right)} c_{i}^{\prime}\left(\delta_{i} \bar{a}_{i}\right) \\
& =\int_{t}^{T_{i}} \mu e^{r \theta} e^{-\left(\delta_{i}+r\right)(\theta-t)} d \theta+\int_{T_{i}}^{\infty}\left(r+\delta_{i}\right) c_{i}^{\prime}\left(\delta_{i} \bar{a}_{i}\right) e^{-\left(\delta_{i}+r\right)(\theta-t)} d \theta
\end{aligned}
$$

The fact that the dates $T_{i}$ differ across sectors is easily derived from the demonstrations of the corollaries in the next subsection.

\section{E.1. Proof of Coroll. 1}

Here we demonstrate Coroll. 1. We first show that two investment profiles cannot cross before one of the sector has reached its maximum potential. One is therefore always higher than the other. We then show that the highest investment profile corresponds to the most expensive sector, or the one with higher abatement potential.

As a lemma, note that the Euler equation

$$
\forall i, \forall t<T_{i}, \quad \frac{d c_{i}^{\prime}\left(x_{i, t}\right)}{d t}=\left(r+\delta_{i}\right) c_{i}^{\prime}\left(x_{i, t}\right)-\mu e^{r t}
$$

implies that if two sectors have the same depreciation rate $\delta_{i}$, if their investment trajectories meet before one of the sectors is decarbonized, then they must be equal for all times before one of the sector is decarbonized:

$$
\begin{aligned}
& \forall(i, j), \delta_{i}=\delta_{j} \text { and } \exists t^{\times} \leq \min \left(T_{i}, T_{j}\right) \text { s. t. } \quad c^{\prime}{ }_{i}\left(x_{i, t^{\times}}\right)=c^{\prime}{ }_{j}\left(x_{j, t^{\times}}\right) \\
& \Longrightarrow \forall t \leq \min \left(T_{i}, T_{j}\right), \quad c^{\prime}{ }_{i}\left(x_{i, t}\right)=c^{\prime}{ }_{j}\left(x_{j, t}\right)
\end{aligned}
$$

This means that the only possibility for two optimal investment trajectories - corresponding to two sectors with the same depreciation rate - to cross at one point in time is after one has reached its maximum abatement potential (Fig. E.6).

Let us prove Coroll. 1(i):

Proof. Let two sectors $\{1,2\}$ be such that they exhibit the same investment cost function, the same depreciation rate, but different abatement potentials:

$$
\forall x>0, \quad c^{\prime}{ }_{1}(x)=c^{\prime}{ }_{2}(x), \quad \delta_{1}=\delta_{2}=\delta, \quad \bar{a}_{1}>\bar{a}_{2}
$$

In the long term, the largest sector is above the small one:

$$
\forall t \geq \max \left(T_{1}, T_{2}\right), \quad(r+\delta) c_{1}^{\prime}\left(\delta \bar{a}_{1}\right)>(r+\delta) c_{2}^{\prime}\left(\delta \bar{a}_{2}\right)
$$

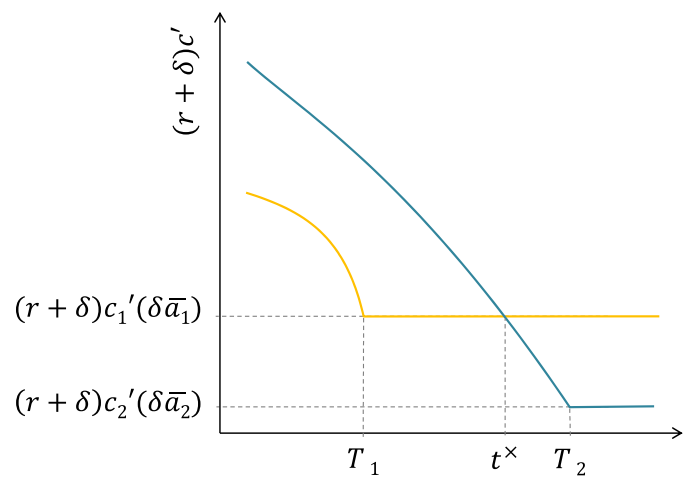

Fig. E.6. Two different investment trajectories corresponding to two sectors with the same depreciation rate crossing after one has reached its maximum abatement potential. 
Suppose that the two investment pathways cross at $t^{\times} \in\left[T_{1}, T_{2}\right],{ }^{15}$ such that (Fig. E.6):

$$
\begin{aligned}
& \left\{\begin{array}{l}
\forall t<t^{\times}, \quad c_{1}^{\prime}\left(x_{1, t}\right) \leq c_{2}^{\prime}\left(x_{2, t}\right) \\
\forall t>t^{\times}, \quad c_{1}^{\prime}\left(x_{1, t}\right)>c^{\prime}{ }_{2}\left(x_{2, t}\right)
\end{array}\right. \\
\Longrightarrow & \forall t<T_{1}, \quad x_{1, t} \leq x_{2, t} \\
\Longrightarrow & \int_{0}^{T_{1}} x_{1, t} e^{-\delta\left(T_{2}-t\right)} d t=\bar{a}_{1}<\int_{0}^{T_{1}} x_{2, t} e^{-\delta\left(T_{2}-t\right)} d t=a_{2, T_{1}}
\end{aligned}
$$

which is incompatible with the constraint that $a_{2, T_{2}} \leq \bar{a}_{2}$ and the assumption that $\bar{a}_{1}<\bar{a}_{2}$. As a result, it is impossible that $c_{1}^{\prime}\left(x_{1, t}\right)$ and $c_{2}^{\prime}\left(x_{2, t}\right)$ cross, and:

$\forall t, c_{1}^{\prime}\left(x_{1, t}\right)>c^{\prime}{ }_{2}\left(x_{2, t}\right)$

Coroll.1 (ii) tackles the similar case of two sectors differing only for the cost of their abatement capital:

$$
\left.\forall x>0, c_{1}^{\prime}(x)<c_{2}^{\prime}(x) \quad \text { (while } \bar{a}_{1}=\bar{a}_{2} \text { and } \delta_{1}=\delta_{2}\right)
$$

The proof is similar: (E.15) holds and (E.16) would imply that $\bar{a}_{2}=a_{2, T_{2}}>\bar{a}_{1}=\bar{a}_{2}$.

Note that Coroll.1 does not prevent any two optimal sectoral investment pathways to cross: the situation pictured in Fig. E.6 may happen for two sectors which differ in cost and abatement potential in different directions $\left(c_{1}^{\prime}>c_{2}^{\prime}\right.$ and bara $\left._{1}<\bar{a}_{2}\right)$ and for sectors for which the depreciation rate of abatement capital differs $\left(\delta_{1} \neq \delta_{2}\right)$.

\section{E.2. Generalization to arbitrary baseline emissions}

In this appendix, we relax the assumption that sectoral emissions are constant to $\bar{a}_{i}$. The general result holds: marginal investment costs differ across sectors, the levelized cost of conserved carbon is different from the social cost of carbon, and it is higher in the sectors that are more difficult to decarbonize. Relaxing the assumption of constant emissions just means that it is more difficult to define which sectors are more difficult to decarbonize.

Replacing $\bar{a}_{i}$ with arbitrary positive emissions $\varepsilon_{i, t}$ in problem (13) yields the following Hamiltonian:

$$
\begin{aligned}
H\left(x_{i, t}, a_{i, t}, m_{t}\right)= & e^{-r t}\left(\sum_{i} c_{i}\left(x_{i, t}\right)+\sum_{i} \lambda_{i, t}\left(a_{i, t}-\varepsilon_{i, t}\right)+\sum_{i} \nu_{i, t}\left(\delta_{i} a_{i, t}-x_{t}\right)\right. \\
& \left.+\mu_{t} \sum_{i}\left(\bar{a}_{i}-a_{i, t}\right)+\phi_{t}\left(m_{t}-B\right)\right)
\end{aligned}
$$

It is easy to verify that first order conditions (E.2), (E.3) and (E.4) are unchanged, as well as the result on the shape of the carbon price (E.6).

However, the slackness condition $\lambda_{i, t}\left(a_{i, t}-\varepsilon_{i, t}\right)=0$ does not result any more in one single date $T_{i}$ in each sector such that $a_{i, t}<\varepsilon_{i, t} \Leftrightarrow t<T_{i}$. In general, we can only say that during some intervals of time, $a_{i, t}<\varepsilon_{i, t}$, and during other time intervals, $a_{i, t}=\varepsilon_{i, t}$. Also, on time intervals when $a_{i, t}=\varepsilon_{i, t}$, investment is now given by $x_{i, t}=\delta_{i} \varepsilon_{i, t}+\dot{\varepsilon}_{i, t}$ (in lieu of $\delta_{i} \bar{a}_{i}$ ).

The good news is that the more general result holds: marginal investment costs are given by the value of abated carbon when net emissions are positive, and the cost of maintaining emissions at their maximum otherwise. (E.11) becomes:

$$
\begin{aligned}
c_{i}^{\prime}\left(x_{i, t}\right)= & \int_{t \mid a_{i, t}<\varepsilon_{i, t}} \mu e^{r \theta} e^{-\left(\delta_{i}+r\right)(\theta-t)} d \theta \\
& +\int_{t \mid a_{i, t}=\varepsilon_{i, t}}\left(r+\delta_{i}\right) c_{i}^{\prime}\left(\delta_{i} \varepsilon_{i, t}+\dot{\varepsilon}_{i, t}\right) e^{-\left(\delta_{i}+r\right)(\theta-t)} d \theta
\end{aligned}
$$

It thus remains the case that if a sector is more difficult to decarbonize, in the sense that the time set under the first integral is longer, and that the maintenance cost in the second integral is higher, then more investment should go to that sector.

To give a more concrete example, assume two sectors 1,2 have the same investment cost function $c_{1}=c_{2}=c$, the same depreciation rate $\delta_{1}=\delta_{2}=\delta$, but different baseline emission $\forall t, \varepsilon_{1, t}>\varepsilon_{2, t}$. Also assume that emission paths are such that the optimal decarbonization schedule follows a clear transition-then-maintenance pattern, in the sense that $\forall i \in\{1,2\}, \exists T_{i}$ suchthat $a_{i, t}<\varepsilon_{i, t} \Longleftrightarrow t<T_{i}$. In that case, all the reasoning in E.1 holds, and the optimal investment cost is higher in sector 1 :

$$
\forall t, c_{1}^{\prime}\left(x_{1, t}\right)>c_{2}^{\prime}\left(x_{2, t}\right)
$$

\footnotetext{
${ }^{15}$ Because $\frac{d c_{i}^{\prime}\left(x_{i, t}\right)}{d t}<0$ in the vicinity of $T_{i}, T_{1}>T_{2}$ is not possible if the curves cross (Fig. E.6)
} 


\section{Appendix F. A perfectly-credible carbon price can decentralize the optimal abatement strategy}

Take the point of view of the owner of one polluting equipment in a sector $i$, facing the credibly announced carbon price schedule $\mu e^{r t}$. One question for this owner is when should the equipment be retrofitted or replaced with zero-carbon capital The following corollary illustrates that the question is easily answered if agents correctly anticipate the prices of carbon and abatement capital:

Corollary 3. Along the optimal pathway, individual forward-looking agents in each sector $i$ are indifferent between investing in abatement capital at any time before $T_{i}$.

Proof. Let $\tau$ be the date when the agent invests in abatement capital. Before $\tau$, the agent pays the carbon price. At $\tau$, she invests in one unit of abatement capital at the price $c_{i}^{\prime}\left(x_{i, \tau}\right)$. At each time period $t$ after $\tau$, she has to maintain its abatement capital, which costs $\delta_{i}{ }^{\prime}{ }_{i}^{\prime}\left(x_{i, t}\right)$. The total discounted cost $V_{i}(\tau)$ of this strategy reads:

$$
V_{i}(\tau)=\mu \tau+e^{-r \tau} c_{i}^{\prime}\left(x_{i, \tau}\right)+\int_{\tau}^{\infty} e^{-r t} \delta_{i} c_{i}^{\prime}\left(x_{i, t}\right) d t
$$

Let us derivative the cost $V$ with respect to the decision variable $\tau$ :

$$
\begin{aligned}
V_{i}^{\prime}(\tau) & =\mu+e^{-r \tau}\left(c_{i}^{\prime}\left(x_{i, \tau}\right)-r \frac{d}{d \tau} c_{i}^{\prime}\left(x_{i, \tau}\right)\right)-e^{-r \tau} \delta_{i} c_{i}^{\prime}\left(x_{i, \tau}\right) \\
& =e^{-r \tau}\left(\left(r+\delta_{i}\right) c_{i}^{\prime}\left(x_{i, \tau}\right)-\frac{d}{d \tau} c_{i}^{\prime}\left(x_{i, \tau}\right)-\mu e^{r_{\tau}}\right) \\
V_{i}^{\prime}(\tau) & =e^{-r \tau} \lambda_{i, \tau} \quad \text { (from eq. E.9) }
\end{aligned}
$$

This last equations implies that $V_{i}^{\prime}(\tau)$ equals zero for any $\tau \leq T_{i}$, and is positive afterwards (E.8). $\quad$ 口

Coroll.3 means that the optimal investment pathways can be decentralized to a market equilibrium by imposing a perfectly credible carbon price path $\mu e^{r t}$ to forward-looking investors.

\section{Appendix G. Overview of the abatement-cost-curve model}

Since the seminal contribution by Nordhaus (1992), a frequent approach to derive the optimal timing of mitigation strategies is to use an abatement cost curve. In this section we find that in this framework the optimal timing and cost of GHG reductions is essentially the same thing as the exponentially-increasing carbon price.

\section{G.1. An abatement cost curve model}

The cost of emission abatement at time $t$ is linked to the abatement $a_{t}$ through an abatement cost curve $\gamma$. The function $\gamma$ is classically convex, positive and twice differentiable:

$$
\begin{aligned}
\forall a_{t}, & \gamma^{\prime \prime}\left(a_{t}\right)>0 \\
\gamma^{\prime}\left(a_{t}\right) & >0 \\
\gamma\left(a_{t}\right) & 0
\end{aligned}
$$

The basic idea behind the abatement cost curve is that some potentials for emission reductions are cheap (e.g. building insulation pays for itself thanks to subsequent savings), while other are more expensive (e.g. upgrading power plants with carbon capture and storage). If potentials are exploited in the merit order - from the cheapest to the most expensive - the marginal cost of doing so $\gamma^{\prime}\left(a_{t}\right)$ is increasing in $a_{t}$, and $\gamma\left(a_{t}\right)$ is convex.

A social planner determines when to abate in order to minimize abatement costs discounted at a given rate $r$, under the constraints set by the abatement potential and the carbon budget:

$$
\begin{array}{lll} 
& \min _{a_{t}} \int_{0}^{\infty} e^{-r t} \gamma\left(a_{t}\right) d t & \\
\text { subject to } & a_{t} \leq \varepsilon_{\text {ref }} & \left(\lambda_{t}\right) \\
& \dot{m}_{t}=\varepsilon_{\text {ref }}-a_{t} & \left(\mu_{t}\right) \\
& m_{t} \leq B & \left(\phi_{t}\right)
\end{array}
$$

We denoted in parentheses the co-state variables and Lagrangian multipliers. 

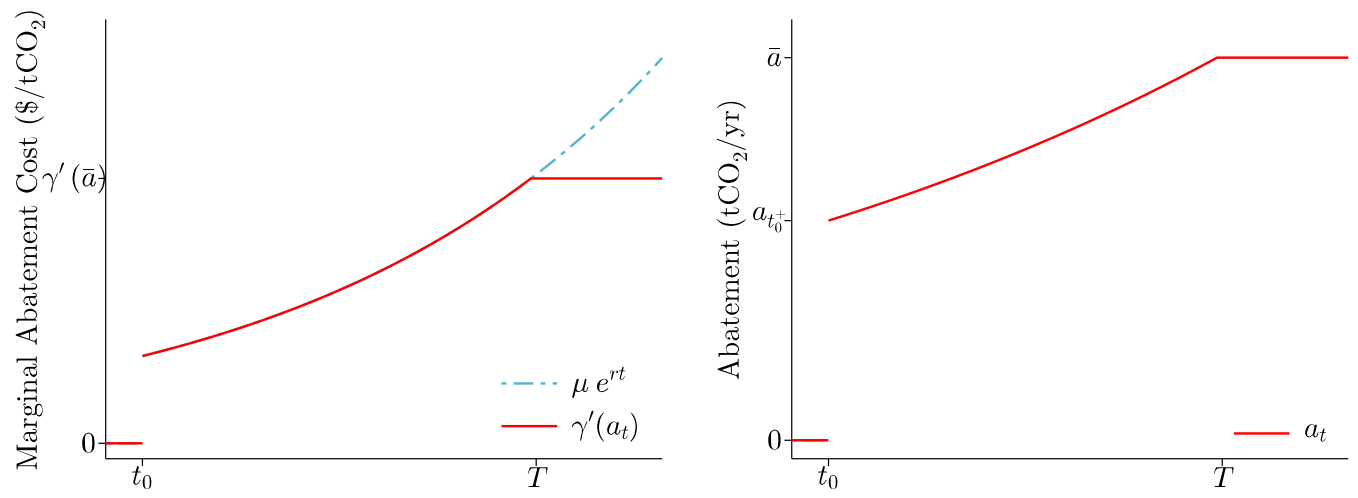

Fig. G.7. Optimal timing and costs of abatement in the abatement-cost-curve framework. Left: Before the potential is reached, abatement efforts are equal to the carbon price and grow over time. Right: When the social planner imposes a carbon price at $t_{0}$, the level of abatement "jumps".

\section{G.2. Result in the abatement cost curve framework}

In the abatement cost curve framework, the optimal abatement cost strategy is to implement abatement options such that the marginal abatement cost is equal to the carbon price $\mu e^{r t}$ at each point in time, until the potential $\varepsilon_{\text {ref }}$ is reached at a date $T$ (G.3):

$$
\gamma^{\prime}\left(a_{t}\right)= \begin{cases}0 & t \leq t_{0} \\ \mu e^{r t} & t_{0}<t<T \\ \gamma^{\prime}\left(\varepsilon_{r e f}\right) & t \geq T\end{cases}
$$

Where $t_{0}$ is the date when the social planner implements the carbon price (Fig. G.7).

Many contributions based on abatement cost curves and numerical optimization factor in some climate change dynamics and damages from climate change, including the DICE model and its extensions discussed in the introduction, without changing these general results.

In the abatement cost curve framework, both the optimal abatement efforts $\gamma\left(a_{t}\right)$ and the abatement level $a_{t}$ thus increase over time. Moreover, abatement decisions can be made at each time step independently, based only on the current carbon price $\mu e^{r t}$ and the abatement cost curve $\gamma$. In particular, the level of abatement jumps when the carbon price is implemented (Fig. G.7). Such jumps are common in the literature on the optimal timing of mitigation. For instance, the last version of DICE finds that the least-cost pathway to reach the $2{ }^{\circ} \mathrm{C}$ target starting a policy in 2010 is to jump from $0 \%$ to $35 \%$ of emission reductions in five years, between 2010 and 2015 - see Figure 9 in Nordhaus and Sztorc (2013) - which we believe is unrealistic. ${ }^{16}$

The (implicit) assumption that abatement can be decided independently at each time step is only valid in cases where abatement action is paid for and delivers emission reduction when the decision is taken, such as driving less or reducing air conditioning. In many cases, such as upgrading to more efficient vehicles or retrofitting buildings, costs are mainly paid when the decision is taken, while annual emissions are reduced over several decades. These actions are better modelled as abatement investment. ${ }^{17}$

\section{G.3. Detailed resolution}

The Hamiltonian associated with (G.2) reads:

$$
H\left(a_{t}, m_{t}\right)=e^{-r t}\left(\gamma\left(a_{t}\right)+\lambda_{t}\left(a_{t}-\varepsilon_{r e f}\right)+\mu_{t}\left(\varepsilon_{r e f}-a_{t}\right)+\phi_{t}\left(m_{t}-B\right)\right)
$$

The first order conditions are:

$$
\begin{aligned}
& \left(\partial a_{t}\right) \gamma^{\prime}\left(a_{t}\right)=\left(\mu_{t}-\lambda_{t}\right) \\
& \left(\partial m_{t}\right) \dot{\mu}_{t}-r \mu_{t}=-\phi_{t}
\end{aligned}
$$

The steady state is reached at a date $T$ when $\dot{m}_{t}=0$, that is when the abatement potential $\varepsilon_{\text {ref }}$ is reached, such that:

\footnotetext{
${ }^{16}$ An other example is Schwoon and Tol (2006), who interestingly allow explicitly for such jumps, in a model that would otherwise be close to the abatement investment model presented in Section 2.

${ }^{17}$ In a recent working paper, Rozenberg (2017) propose a model to analyse instantaneous reductions and abatement investment in the same framework (but their model does not allow to compare investment in different sectors).
} 


$$
\begin{aligned}
& \forall t<T, \quad a_{t}<\varepsilon_{r e f} \text { and } m_{t}<B \\
& \forall t \geq T, \quad a_{t}=\varepsilon_{r e f} \text { and } m_{t}=B
\end{aligned}
$$

As the associated Lagrangian multiplier, $\phi_{t}$ is zero before the carbon budget is reached (complementary slackness condition):

$$
\begin{aligned}
\forall t, & \phi_{t} \cdot\left(m_{t}-B\right)=0 \\
\Longrightarrow & \forall t<T, \quad \phi_{t}=0
\end{aligned}
$$

This means that the present value of carbon $\mu_{t}$ is constant while the carbon budget has not been reached (G.6):

$$
\forall t<T, \quad \mu_{t}=\mu e^{r t}
$$

For the same reason, $\lambda_{t}$ is zero before the sectoral potential becomes binding:

$$
\begin{aligned}
& \forall t, \quad \lambda_{t} \cdot\left(a_{t}-\varepsilon_{r e f}\right)=0 \\
& \Longrightarrow \forall t<T, \quad \lambda_{t}=0
\end{aligned}
$$

Combining (G.5), (G.8), and (G.9), one gets (G.3).

\section{References}

Acemoglu, D. Aghion, P., Bursztyn, L., Hemous, D., 2012. The environment and directed technical change. Am. Econ. Rev. 102 (1), $131-166$.

Allen, M.R., Frame, D.J., Huntingford, C., Jones, C.D., Lowe, J.A., Meinshausen, M., Meinshausen, N., 2009. Warming caused by cumulative carbon emissions towards the trillionth tonne. Nature 458 (7242), 1163-1166.

Ambrosi, P., Hourcade, J.-C., Hallegatte, S., Lecocq, F., Dumas, P., Ha Duong, M., 2003. Optimal control models and elicitation of attitudes towards climate damages. Environ. Model. Assess. 8 (3), 133-147.

Audoly, R., Vogt-Schilb, A., Guivarch, C., Pfeiffer, A., 2017. Pathways toward Zero-Carbon Electricity Required for Climate Stabilization. Inter-American Development Bank Working Paper 827.

Bosello, F., Carraro, C., De Cian, E., 2010. Climate policy and the optimal balance between mitigation, adaptation and unavoided damage. Clim. Change Econ. 01 (02), $71-92$.

Bramoullé, Y., Olson, L.J., 2005. Allocation of pollution abatement under learning by doing. J. Public Econ. 89 (9-10), 1935-1960.

Bruin, K.C.d., Dellink, R.B., Tol, R.S.J., 2009. AD-DICE: an implementation of adaptation in the DICE model. Clim. Change 95 (1-2), 63-81.

Brunner, S., Flachsland, C., Marschinski, R., 2012. Credible commitment in carbon policy. Clim. Policy 12 (2), 255-271.

Davis, S.J., Socolow, R.H., 2014. Commitment accounting of CO2 emissions. Environ. Res. Lett. 9 (8), 084018.

del Rio Gonzalez, P., 2008. Policy implications of potential conflicts between short-term and long-term efficiency in CO2 emissions abatement. Ecol. Econ. 65 (2), $292-303$.

Dietz, S., Stern, N., 2014. Endogenous growth, convexity of damages and climate risk: How Nordhaus framework supports deep cuts in carbon emissions. Econ. J..

Espagne, E., Perrissin-Fabert, B., Pottier, A., Nadaud, F., Dumas, P., 2012. Disentangling the Stern/Nordhaus Controversy: Beyond the Discounting Clash. Working Paper 2012.61, Fondazione Eni Enrico Mattei.

Fischer, C. Withagen, C., Toman, M., 2004. Optimal investment in clean production capacity. Environ. Resour. Econ. 28 (3), $325-345$.

G7, 2015. Leaders Declaration after the G7 Summit held in Germany.

Gould, J.P., 1968. Adjustment costs in the theory of investment of the firm. Rev. Econ. Stud. 35 (1), 47.

Goulder, L.H., Mathai, K., 2000. Optimal CO2 abatement in the presence of induced technological change. J. Environ. Econ. Manag. 39 (1), 1-38.

Grubb, M., Chapuis, T., Ha-Duong, M., 1995. The economics of changing course: Implications of adaptability and inertia for optimal climate policy. Energy Policy 23 (45), 417-431.

Heal, G.M., Millner, A., 2014. Agreeing to disagree on climate policy. Proc. Natl. Acad. Sci. 111 (10), 3695-3698.

Hoel, M., 1996. Should a carbon tax be differentiated across sectors? J. Public Econ. 59 (1), 17-32.

Hwang, I.C., Reynès, F., Tol, R.S.J., 2013. Climate policy under fat-tailed risk: an application of DICE. Environ. Resour. Econ. 56 (3), $415-436$.

IEA, 2015. Policies and measures database. Tech. rep.

IPCC, 2007. Summary for policymakers. In: Climate change 2007: Mitigation. Contribution of working group III to the fourth assessment report of the inter-

governmental panel on climate change. Cambridge University Press, Cambridge, UK and New York, USA.

IPCC, 2014a. Annex II: Metrics and methodology. In: Climate Change 2014, Mitigation of Climate Change. Contribution of Working Group III to the Fifth Assessment Report of the Intergovernmental Panel on Climate Change, cambridge university press Edition. [Edenhofer, O., R. Pichs-Madruga, Y. Sokona, E. Farahani, S. Kadner, K. Seyboth, A. Adler, I. Baum, S. Brunner, P. Eickemeier, B. Kriemann, J. Savolainen, S. Schlmer, C. von Stechow, T. Zwickel and J.C. Minx (eds.)]. Cambridge, United Kingdom and New York, NY, USA.

IPCC, 2014b. Summary for Policymakers. In: Climate Change 2014, Synthesis Report. Contribution of Working Groups I, II and III to the Fifth Assessment Report of the Intergovernmental Panel on Climate Change, cambridge university press Edition. Cambridge, United Kingdom and New York, NY, USA.

Iyer, G., Hultman, N., Eom, J., Mcjeon, H., Patel, P., Clarke, L., 2014. Diffusion of low-carbon technologies and the feasibility of long-term climate targets. Technol. Forecast. Social. Change.

Jaccard, M., Rivers, N., 2007. Heterogeneous capital stocks and the optimal timing for CO2 abatement. Resour. Energy Econ. 29 (1), 1-16.

Jacoby, H.D., Sue Wing, I., 1999. Adjustment time, capital malleability and policy cost. Energy J. 20, 73-92.

Jorgenson, D., 1967. The theory of investment behavior. In: Determinants of investment behavior. NBER.

Keller, K., Bolker, B.M., Bradford, D.F., 2004. Uncertain climate thresholds and optimal economic growth. J. Environ. Econ. Manag. 48 (1), $723-741$.

Kolstad, C.D., 1996. Learning and stock effects in environmental regulation: the case of greenhouse gas emissions. J. Environ. Econ. Manag. 31 (1), 1-18.

Kverndokk, S., Rosendahl, K.E., 2007. Climate policies and learning by doing: Impacts and timing of technology subsidies. Resour. Energy Econ. 29 (1), 58-82.

Lecocq, F., Shalizi, Z., 2014. The economics of targeted mitigation in infrastructure. Clim. Policy 14 (2), 187-208.

Lecocq, F., Hourcade, J., Ha-Duong, M., 1998. Decision making under uncertainty and inertia constraints: sectoral implications of the when flexibility. Energy Econ. 20 (5-6), 539-555.

Lemoine, D., Traeger, C., 2014. Watch your step: optimal policy in a tipping climate. Am. Econ. J.: Econ. Policy 6 (1), 137-166.

Lucas Jr., R.E., 1967. Adjustment costs and the theory of supply. J. Political Econ. 75 (4), 321-334.

Manne, A.S., Richels, R.G., 1992. Buying Greenhouse Insurance: The Economic Costs of Carbon Dioxide Emission Limits. MIT Press, Cambridge, Mass.

Matthews, H.D., Gillett, N.P., Stott, P.A., Zickfeld, K., 2009. The proportionality of global warming to cumulative carbon emissions. Nature 459 (7248), 829-832.

McCollum, D., Nagai, Y., Riahi, K., Marangoni, G., Calvin, K., Pietzcker, R., Van Vliet, J., Van Der Zwaan, B., 2013. Energy investments under climate policy: a comparison of global models. Clim. Change Econ. 04 (04), 1340010.

McKinsey, Company, 2009. Pathways to a low-carbon economy: Version 2 of the global greenhouse gas abatement cost curve. Tech. rep.

Ministry of Finance, 2015. Carbon tax. Province of British Columbia.

Mussa, M., 1977. External and internal adjustment costs and the theory of aggregate and firm investment. Economica 44 (174), $163-178$. 
NCE, 2014. Better growth better climate: the new climate economy report, New Climate Economy Edition. Washington DC, USA

Nordhaus, W.D., 1991. To slow or not to slow: The economics of the greenhouse effect. Econ. J. 101 (407), $920-937$.

Nordhaus, W.D., 1992. An optimal transition path for controlling greenhouse gases. Science 258 (5086), 1315-1319.

Nordhaus, W.D., Sztorc, P., 2013. DICE 2013R: Introduction and user’s manual. 〈http://dicemodel.net〉.

Philibert, C., 2007. Technology penetration and capital stock turnover: Lessons from IEA scenario analysis. OECD Working Paper.

Pindyck, R.S., 2013. Climate change policy: what do the models tell us. J. Econ. Lit. 51 (3), 860-872.

Popp, D., 2004. ENTICE: endogenous technological change in the DICE model of global warming. J. Environ. Econ. Manag. 48 (1), $742-768$.

Riahi, K., Kriegler, E., Johnson, N., Bertram, C., den Elzen, M., Eom, J., Schaeffer, M., Edmonds, J., Isaac, M., Krey, V., Longden, T., Luderer, G., Méjean, A., McCollum, D.L., Mima, S., Turton, H., van Vuuren, D.P., Wada, K., Bosetti, V., Capros, P., Criqui, P., Hamdi-Cherif, M., Kainuma, M., Edenhofer, O., 2015. Locked into Copenhagen pledgesImplications of short-term emission targets for the cost and feasibility of long-term climate goals. Technological Forecasting and Social Change 90, Part A, $8-23$.

Rosendahl, K.E. 2004. Cost-effective environmental policy: implications of induced technological change. J. Environ. Econ. Manag. 48 (3), 1099-1121.

Rozenberg, J., Vogt-Schilb, A., Hallegatte, S., 2017. Instrument Choice and Stranded Assets in the Transition to Clean Capital. Inter-American Development Bank Working Paper 782 .

Schwoon, M., Tol, R.S., 2006. Optimal CO2-abatement with socio-economic inertia and induced technological change. Energy J. $27,4$.

Slechten, A., 2013. Intertemporal links in cap-and-trade schemes. J. Environ. Econ. Manag. 66 (2), 319-336.

Stern, N., 2013. The structure of economic modeling of the potential impacts of climate change: Grafting gross underestimation of risk onto already narrow science models: Grafting gross underestimation of risk onto already narrow science models. J. Econ. Lit. 51 (3), 838-859.

Stern, N.H., 2006. Stern review: the economics of climate change. HM Treas. Lond.

UNFCCC, 2016. Report of the Conference of the Parties on its twenty-first session, held in Paris from 30 November to 13 December 2015. FCCC /CP/2015/10, United Nations Framework Convention on Climate Change.

van der Zwaan, B.C.C., Gerlagh, R., Klaassen, G., Schrattenholzer, L., 2002. Endogenous technological change in climate change modelling. Energy Econ. 24 (1), 1-19.

Vogt-Schilb, A., Hallegatte, S., 2014. Marginal abatement cost curves and the optimal timing of mitigation measures. Energy Policy 66, 645-653.

Vogt-Schilb, A., Hallegatte, S., de Gouvello, C., 2015. Marginal abatement cost curves and the quality of emission reductions: a case study on Brazil. Clim. Policy 15 (6), $703-723$.

Vogt-Schilb, A., Meunier, G., Hallegatte, S., 2012. How inertia and limited potentials affect the timing of sectoral abatements in optimal climate policy. World Bank Policy Research Working Paper 6154.

Wigley, T.M.L., Richels, R., Edmonds, J.A., 1996. Economic and environmental choices in the stabilization of atmospheric CO2 concentrations. Nature 379 (6562), $240-243$.

Williams, J.H., DeBenedictis, A., Ghanadan, R., Mahone, A., Moore, J., Morrow, W.R., Price, S., Torn, M.S., 2012. The technology path to deep greenhouse gas emissions cuts by 2050: The pivotal role of electricity. Science 335 (6064), 53-59.

Williams, R., 2010. Setting the initial time-profile of climate policy: The economics of environmental policy phase-ins. Working Paper 16120, National Bureau of Economic Research.

World Bank, 2012. Inclusive green growth: the pathway to sustainable development. World Bank, Washington, D.C.

World Bank, 2014. State and Trends of Carbon Pricing 2014. The World Bank, Washington DC, USA.

World Bank, 2015. Decarbonizing Development: Three Steps to a Zero-Carbon Future. World Bank Publications.

WRI, 2015. CAIT 2.0: WRI's climate data explorer. World Resources Institute 〈http://cait2.wri.org

Zickfeld, K., Eby, M., Matthews, H.D., Weaver, A.J., 2009. Setting cumulative emissions targets to reduce the risk of dangerous climate change. Proc. Natl. Acad. Sci. USA 106 (38), 16129-16134. 